Manuscript received July 2, 2014; accepted for publication October 28 , 2015; published online January 27, 2016.

'Ph.D. Candidate, Centre for Offshore Foundation Systems, The Univ. of Western Australia, 35 Stirling Highway, Crawley, Perth, Western Australia 6009, e-mail: 21164085@student.uwa.edu.au

${ }^{2}$ Associate Professor, Centre for Offshore Foundation Systems, The Univ. of Western Australia, 35 Stirling Highway, Crawley, Perth, Western Australia 6009 (Corresponding author), e-mail: conleth.oloughlin@uwa.edu.au

${ }^{3}$ Ph.D. Candidate, Centre Centre for Offshore Foundation Systems, The Univ. of Western Australia, 35 Stirling Highway, Crawley, Perth, Western Australia 6009, e-mail: 21164067@student.uwa.edu.au

${ }^{4}$ Ph.D. Candidate, Centre for Offshore Foundation Systems, The Univ. of Western Australia, 35 Stirling Highway, Crawley, Perth, Western Australia 6009, e-mail: 21161881@student.uwa.edu.au

${ }^{5}$ Professor, Centre for Offshore Foundation Systems, The Univ. of Western Australia, 35 Stirling Highway, Crawley, Perth, Western Australia 6009, e-mail: christophe.gaudin@uwa.edu.au

${ }^{6}$ Professor, Centre for Offshore Foundation Systems, The Univ. of Western Australia, 35 Stirling Highway, Crawley, Perth, Western Australia 6009, e-mail: david.white@uwa.edu.au
Anthony P. Blake, ${ }^{1}$ Conleth D. O'Loughlin, ${ }^{2}$ John P. Morton, ${ }^{3}$ Colm O'Beirne, ${ }^{4}$

Christophe Gaudin, ${ }^{5}$ and David J. White ${ }^{6}$

\section{In Situ Measurement of the Dynamic Penetration of Free-Fall Projectiles in Soft Soils Using a Low-Cost Inertial Measurement Unit}

\section{Reference}

Blake, A. P., O’Loughlin, C. D., Morton, J. P., O’Beirne, C., Gaudin, C., and White, D. J., “In Situ Measurement of the Dynamic Penetration of Free-Fall Projectiles in Soft Soils Using a Low-Cost Inertial Measurement Unit," Geotechnical Testing Journal, Vol. 39, No. 2, 2016, pp. 235-251, doi:10.1520/ GTJ20140135. ISSN 0149-6115

\section{ABSTRACT}

Six degree-of-freedom motion data from projectiles free-falling through water and embedding in soft soil are measured using a low-cost inertial measurement unit, consisting of a tri-axis accelerometer and a three-component gyroscope. A comprehensive framework for interpreting the measured data is described and the merit of this framework is demonstrated by considering sample test data for free-falling projectiles that gain velocity as they fall through water and self-embed in the underlying soft clay. The paper shows the importance of considering such motion data from an appropriate reference frame by showing good agreement in embedment depth data derived from the motion data with independent direct measurements. Motion data derived from the inertial measurement unit are used to calibrate a predictive model for calculating the final embedment depth of a dynamically installed anchor.

\section{Keywords}

anchor, ball, dynamic, free fall, inertial measurement unit, MEMS, accelerometer, gyroscope, offshore, characterization 


\section{Nomenclature}

$a=$ resultant linear acceleration

$a_{b z}=$ linear acceleration coincident with the body frame $z$-axis

$a_{x}=$ linear acceleration coincident with the inertial frame $x$-axis

$a_{y}=$ linear acceleration coincident with the inertial frame $y$-axis

$a_{z}=$ linear acceleration coincident with the inertial frame $z$-axis

$A=$ acceleration measurement

$A_{b x}=$ acceleration measurement coincident with the body frame $x$-axis

$A_{b y}=$ acceleration measurement coincident with the body frame $y$-axis

$A_{b z}=$ acceleration measurement coincident with the body frame $z$-axis

$A_{p}=$ projected area

$A_{s}=$ shaft area

AVTM $=$ angular velocity transformation matrix

$A_{x}=$ acceleration measurement coincident with the inertial frame $x$-axis

$A_{y}=$ acceleration measurement coincident with the inertial frame $y$-axis

$A_{z}=$ acceleration measurement coincident with the inertial frame $z$-axis

$C_{d}=$ drag coefficient

$d=$ diameter

$\mathrm{DCM}=$ direction cosine matrix

DEPLA $=$ dynamically embedded plate anchor

$\mathrm{DoF}=$ degrees of freedom

$\mathrm{DPA}=$ deep penetrating anchor

$F_{b}=$ soil buoyancy

$F_{\text {bear }}=$ bearing resistance

$F_{d}=$ drag resistance

$F_{\text {frict }}=$ frictional resistance

$g=$ Earth's gravitational acceleration

IFFS $=$ instrumented free-falling sphere

IMU $=$ inertial measurement unit

$m=$ mass

MEMS $=$ micro-electro-mechanical system

$n, n_{l}=$ strain rate parameters

$N=$ bearing capacity factor

$N_{\text {ball }}=$ piezoball bearing factor

$N_{k t}=$ piezocone bearing factor

$R_{f}=$ strain rate function

$R_{b}^{i}=$ direction cosine matrix (body frame to inertial frame)

$R_{x}=$ roll matrix

$R_{y}=$ pitch matrix

$R_{z}=$ yaw matrix $s=$ distance traveled in the direction of motion

$s_{0}=$ initial distance traveled in the direction of motion

$s_{b z}=$ vertical distance traveled coincident with the body frame

$s_{u}=$ undrained shear strength

$s_{z}=$ vertical distance traveled coincident with the inertial frame

$s_{z 0}=$ initial vertical distance traveled coincident with the inertial-frame

$t=$ time

$T_{b}^{i}=$ angular velocity transformation matrix (body frame to inertial frame)

$v=$ resultant velocity

$v_{b z}=$ velocity coincident with the body frame $z$-axis

$v_{x}=$ velocity coincident with the inertial frame $x$-axis

$v_{x 0}=$ initial velocity coincident with the inertial frame $x$-axis

$v_{y}=$ velocity coincident with the inertial frame $y$-axis

$v_{y 0}=$ initial velocity coincident with the inertial frame $y$-axis

$v_{z}=$ velocity coincident with the inertial frame $z$-axis

$v_{z 0}=$ initial velocity coincident with the inertial frame $z$-axis

$W_{s}=$ submerged weight

$x_{b}=$ body frame $x$-axis

$x=$ inertial frame $x$-axis

$y=$ inertial frame $y$-axis

$y_{b}=$ body frame $y$-axis

$z=$ inertial frame $z$-axis, depth

$z_{b}=$ body frame $z$-axis

$z_{e}=$ embedment depth

$\alpha=$ interface friction ratio

$\beta=$ power law strain rate parameter

$\gamma=$ unit weight of soil

$\gamma^{\prime}=$ effective unit weight of soil

$\dot{\gamma}=$ strain rate

$\Delta \theta=$ difference between body-frame and inertial-frame pitch angles

$\Delta \phi=$ difference between body-frame and inertial-frame roll angles

$\theta=$ pitch angle coincident with the inertial frame

$\theta_{\text {acc }}=$ pitch angle coincident with the inertial frame (derived from accelerometer measurements)

$\theta_{b}=$ pitch angle coincident with the body frame

$\theta_{b 0}=$ initial pitch angle coincident with the body frame

$\mu=$ resultant tilt angle (relative to Earth's gravity)

$\rho_{s}=$ soil density

$\psi=$ yaw angle coincident with the inertial frame

$\psi_{b}=$ yaw angle coincident with the body frame

$\psi_{b 0}=$ initial yaw angle coincident with the body frame

$\omega_{b x}=$ rotation rate about the body-frame $x$-axis 
$\omega_{b y}=$ rotation rate about the body-frame $y$-axis

$\omega_{b z}=$ rotation rate about the body-frame $z$-axis

$\omega_{x}=$ rotation rate about the inertial-frame $x$-axis

$\omega_{y}=$ rotation rate about the inertial-frame $y$-axis

$\omega_{z}=$ rotation rate about the inertial-frame $z$-axis

$\phi=$ roll angle coincident with the inertial frame

$\phi_{\text {acc }}=$ roll angle coincident with the inertial frame

(derived from accelerometer measurements)

$\phi_{b}=$ roll angle coincident with the body frame

$\phi_{b 0}=$ initial roll angle coincident with the body frame

\section{Introduction}

An inertial measurement unit (IMU) is an electromechanical device that measures an object's six degrees of freedom (6DoF) motion in three-dimensional space using a combination of gyroscope and accelerometer sensors. The development of micro-electromechanical systems (MEMS) gyroscope and accelerometer technology has significantly reduced the cost, size, weight, and power consumption of IMUs, and enhanced their robustness.

MEMS accelerometers and gyroscopes are typically fabricated on single-crystal silicon wafers using micromachining to etch defined patterns on a silicon substrate. These patterns take the form of small proof masses that are free from the substrate and surrounded by fixed plates. The proof mass is connected to a fixed frame by flexible beams, effectively forming spring elements. Low-cost consumer grade MEMS gyroscopes typically use vibrating mechanical elements to sense angular rotation rate. During operation the proof mass is resonated with constant amplitude in the "drive direction" by an external sinusoidal electrostatic or electromagnetic force. Angular rotation then induces a matched-frequency sinusoidal Coriolis force orthogonal to the drive-mode oscillation and the axis of rotation. The Coriolis force deflects the proof mass and plates connected to the proof mass move between the fixed plates in the sense mode. The operational principle for MEMS accelerometers is much simpler; accelerations acting on the proof mass cause it to displace, and plates connected to the proof mass move between fixed plates. For both sensors, the movement of the plates cause a differential capacitance that is measured by integrated electronics and is output as a voltage that is proportional to either the applied angular rotation rate (in the case of MEMS gyroscopes) or acceleration (in the case of MEMS accelerometers). The operational principles of the MEMS accelerometers and gyroscopes as described above are shown schematically in Fig. 1.

Common applications of low-cost IMUs featuring MEMS technology include: inertial navigation systems (e.g., remotely operated vehicles, autonomous underwater vehicles, and unmanned aerial vehicles), active safety systems (electronic
FIG. 1 Schematic representation of the operational principle of (a) MEMS accelerometers and (b) MEMS gyroscopes.

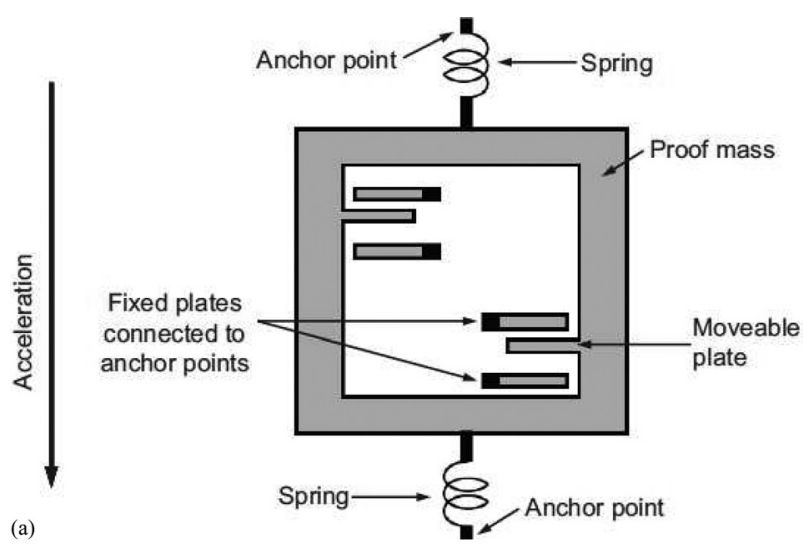

(a)

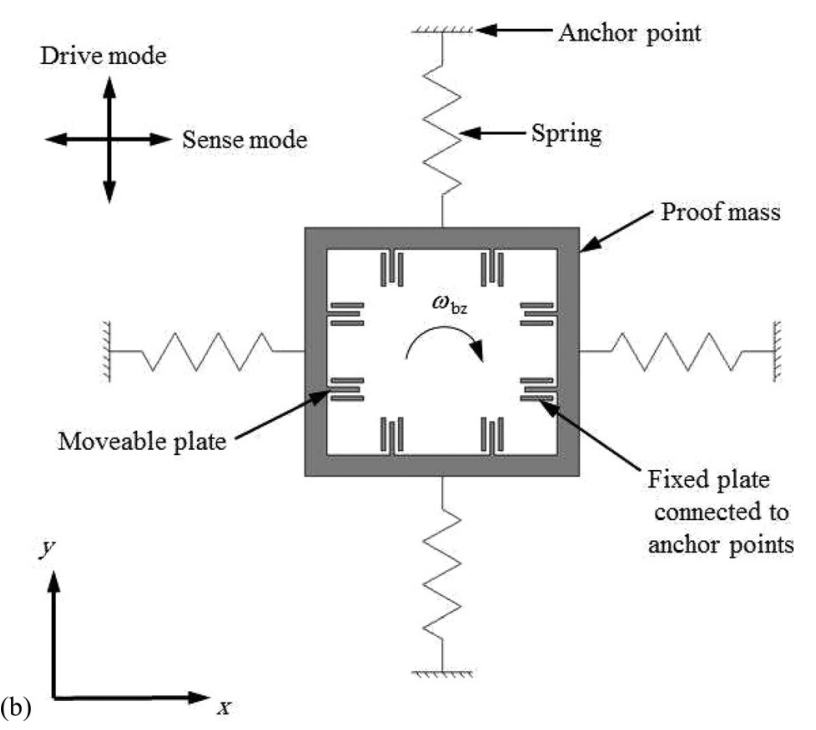

stability control and traction control in motor vehicles), and motion-activated user interfaces (e.g., smartphones, game controllers and tablet computers). The use of low-cost 6DoF IMUs for geotechnical applications has not been reported. However, MEMS accelerometers have been used for in situ geotechnical applications to measure inclinations in boreholes (Bennett et al. 2009), soil displacement associated with rapid uplift of footings (Levy and Richards 2012), and the motion of free-falling cone penetrometers (e.g., Stegmann et al. 2006; Stephan et al. 2012; Steiner et al. 2014). In geotechnical centrifuge modeling MEMS accelerometers have been used to measure the acceleration response of free-falling projectiles in clay (Chow et al. 2014; O'Loughlin et al. 2014), earthquake accelerations (Stringer et al. 2010; Cilingir and Madabhushi 2011), and rotation of structures during slow lateral cycling and dynamic shaking (Allmond et al. 2014). Although accelerometers are often used to measure the rotation of objects at constant acceleration, they cannot distinguish rotation from linear acceleration if the object's orientation and acceleration is changing. However, gyroscopes are 
unaffected by linear acceleration, and the rotation of accelerating objects can be derived from their measurements. Hence, the combination of accelerometer and gyroscope measurements enables an object's linear acceleration to be determined relative to a reference frame that is not necessarily coincident with the reference frame of the object. This becomes important for the applications considered in this paper, where dynamically installed anchors and a free-falling sphere (collectively referred to as "projectiles" from this point forward) free fall through water and bury in the underlying soil. As described later, the motion response of the projectile must be considered from the appropriate reference frame. From the viewpoint of the hydrodynamic and geotechnical resistances acting on the projectile during motion, it becomes important to consider the projectile's trajectory. In contrast, from a geotechnical design viewpoint the final depth and orientation of the projectile relative to a fixed inertial frame of reference (with an axis in the direction of Earth's gravity) is important as this will dictate the local soil strength in the vicinity of the embedded projectile and (for the case of the anchors) how this strength will be mobilized during loading.

This paper describes a custom-design, low-cost MEMSbased IMU and presents a comprehensive framework for interpreting the IMU measurements (which are made in the body frame of reference) so that they are coincident with a fixed inertial frame of reference. The framework is implemented to establish rotation, acceleration and velocity profiles for the projectiles during free fall in water and embedment in soil. The final projectile embedment depths established from the IMU data are compared with direct measurements, and the merit of collecting motion data during dynamic penetration is demonstrated by using such data to verify the appropriateness of an embedment prediction model for dynamically installed anchors.

\section{Free-Falling Projectiles}

\section{DEEP PENETRATING ANCHORS}

The deep penetrating anchor (DPA) is a proprietary term for a dynamically installed anchor design. The DPA is designed so that, after release from a designated height above the seafloor, it will penetrate to a target depth in the seabed using the kinetic energy gained through free fall. The DPA data considered here are from tests using a 1:20 reduced scale model anchor based on an idealized design proposed by Lieng et al. (1999). The model DPA (see Fig. 2), was fabricated from mild steel and had an overall length of $750 \mathrm{~mm}$, a shaft diameter of $60 \mathrm{~mm}$ and a mass of $20.7 \mathrm{~kg}$. The anchor had an ellipsoidal tip and featured four clipped delta type flukes (separated by $90^{\circ}$ in plan) with a forward swept trailing edge. The anchor shaft was solid with the exception of a watertight cylindrical void toward the top to house the IMU.

\section{FIG. 2 Deep penetrating anchor.}

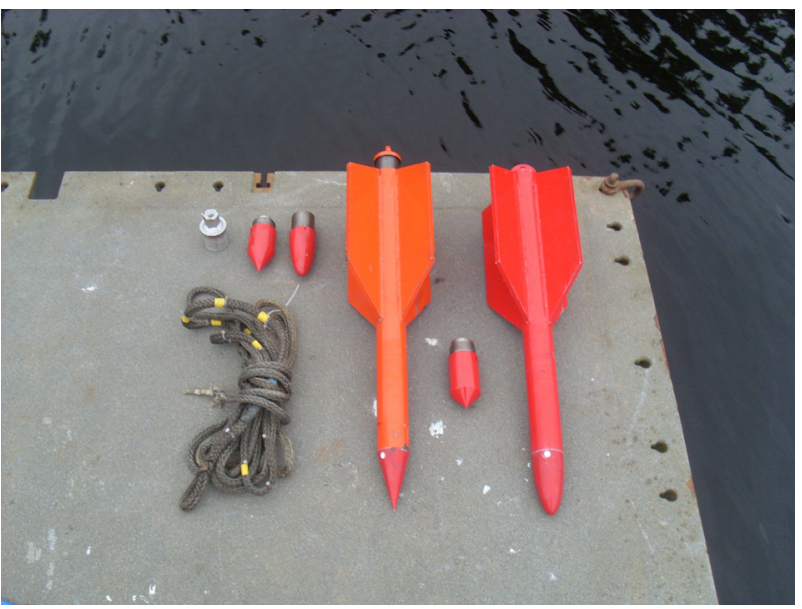

\section{DYNAMICALLY EMBEDDED PLATE ANCHORS}

The dynamically embedded plate anchor (DEPLA; O'Loughlin et al. 2013(a)) is an anchoring system that combines the capacity advantages of vertically loaded anchors with the installation advantages of dynamically installed anchors. The DEPLA comprises a removable central shaft or "follower" and a set of four flukes (see Fig. 3). A stop cap at the upper end of the follower prevents it from falling through the DEPLA sleeve and a shear pin connects the flukes to the follower. The DEPLA is installed in a similar manner as the DPA, but after coming to rest in the seabed the follower retriever line is tensioned, which causes the shear pin to part (if not already broken during impact) allowing the follower to be retrieved for the next installation while leaving the anchor flukes vertically embedded in the seabed. These embedded anchor flukes constitute the load bearing element as a plate anchor.

In the tests considered here the DEPLA was modeled at a reduced scale of 1:4.5 and fabricated from mild steel. The follower (and hence DEPLA) length was $2 \mathrm{~m}$, the follower diameter was $160 \mathrm{~mm}$, the fluke (plate) diameter was $800 \mathrm{~mm}$ and the overall mass was $388.6 \mathrm{~kg}$. As with the DPA, the DEPLA

FIG. 3 Dynamically embedded plate anchor.

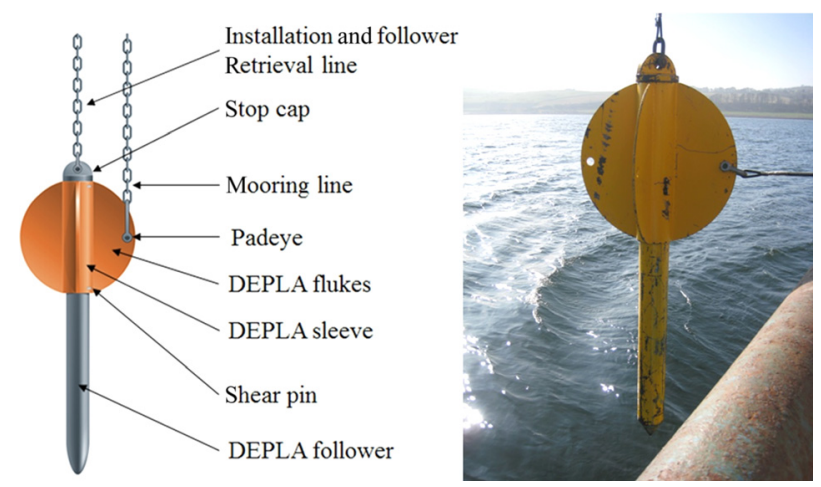


FIG. 4

Instrumented free-falling sphere.

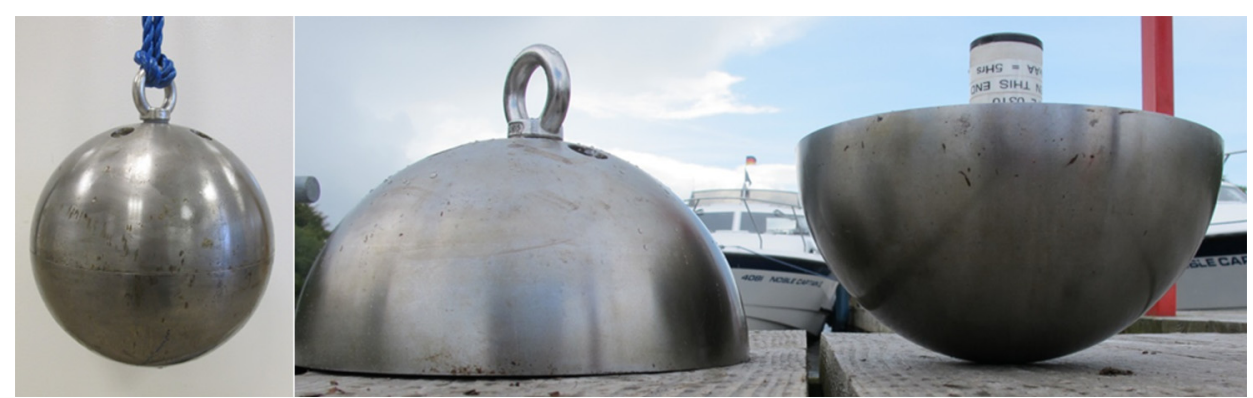

follower was solid with the exception of a cylindrical void at the top to house the IMU. The model DEPLA is shown in Fig. $\mathbf{3}$.

\section{INSTRUMENTED FREE-FALLING SPHERE}

The instrumented free-falling sphere (IFFS) has been proposed as an in situ characterization tool for soft soils (Morton and O'Loughlin 2012; O'Loughlin et al. 2014). The IFFS is a steel sphere that dynamically embeds in soft soil in a manner similar to dynamically installed anchors. IMU data measured during embedment in soil can be used to estimate undrained shear strength. As such, the IFFS is conceptually similar to a free fall cone penetrometer, but the simple spherical geometry of the IFFS is beneficial as the projected area does not change with rotation and the bearing factor for the ball is more tightly constrained than for the cone. The IFFS data considered here are from tests using a $250 \mathrm{~mm}$ diameter mild steel sphere with a mass of $50.8 \mathrm{~kg}$. The IFFS was fabricated as two hemispheres (that could be bolted together) with an internal vertically orientated cylindrical void to accommodate the IMU (see Fig. 4).

\section{Inertial Measurement Unit}

The IMU was used to measure projectile accelerations and rotation rates during free fall in the water column and embedment in the soil. The IMU (see Fig. 5) includes a 16-bit three-component MEMS rate gyroscope (ITG 3200) and a 13bit three-axis MEMS accelerometer (ADXL 345). The gyroscope had a resolution of $0.07^{\circ} / \mathrm{s}$ with a measurement range of $\pm 2000^{\circ} \mathrm{s}$. The accelerometer had a resolution of $0.04 \mathrm{~m} / \mathrm{s}^{2}$ with a measurement range of $\pm 16 \mathrm{~g}$. Data were logged by an mbed micro controller with an ARM processor to a $2-\mathrm{GB}$ SD card at $400 \mathrm{~Hz}$. Internal batteries were capable of powering the logger for up to $4 \mathrm{~h}$. The IMU was contained in a watertight aluminum tube $185 \mathrm{~mm}$ long and $42 \mathrm{~mm}$ in diameter and was located in a void (with the same dimensions) within the projectile. The IMU had a mass of approximately $0.5 \mathrm{~kg}$ (including the batteries).

The accelerometer and gyroscope are aligned with the body frame of the projectile and the IMU as shown in Fig. 6 (for the DEPLA). The body frame is a reference frame with three orthogonal axes $x_{b}, y_{b}$, and $z_{b}$ that are common to both the IMU and the projectile and where the $z_{b}$-axis is parallel to the direction of earth's gravity when the projectile is hanging vertically. The accelerometer measures accelerations $A_{b x}, A_{b y}$, and $A_{b z}$ in the body frame along these three axes. These accelerometer measurements include a component of gravitational acceleration (depending on the orientation of the accelerometer) and linear acceleration. The gyroscope measures angular velocities $\omega_{b x}, \omega_{b y}$, and $\omega_{b z}$ in the body frame about the same orthogonal axes. Accelerometers are often used to measure the rotation of quasi-static objects but cannot distinguish rotation from linear acceleration if an object is in motion. However, gyroscopes are unaffected by linear acceleration and the rotation of objects in motion can be derived from their measurements.

FIG. 5

Inertial measurement unit.

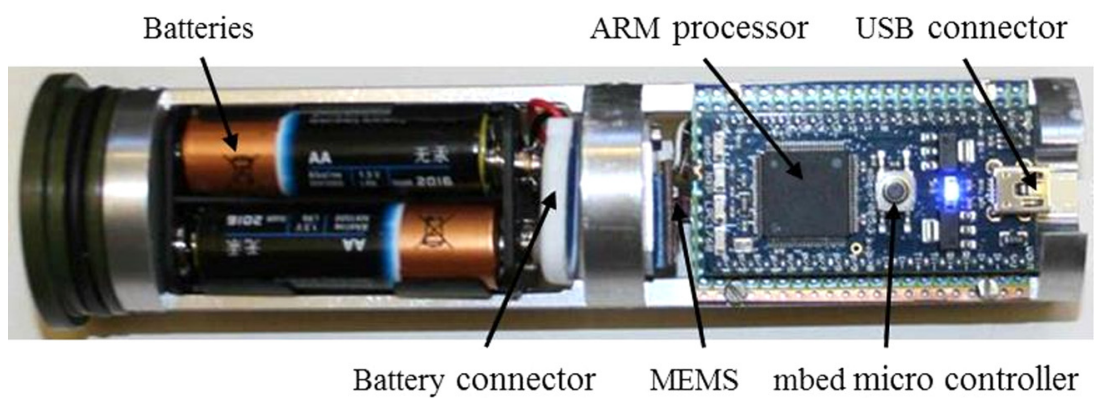

Copyright by ASTM Int'l (all rights reserved); Thu May 4 02:35:02 EDT 2017 
FIG. 6 Measurements made in the body frame of reference.

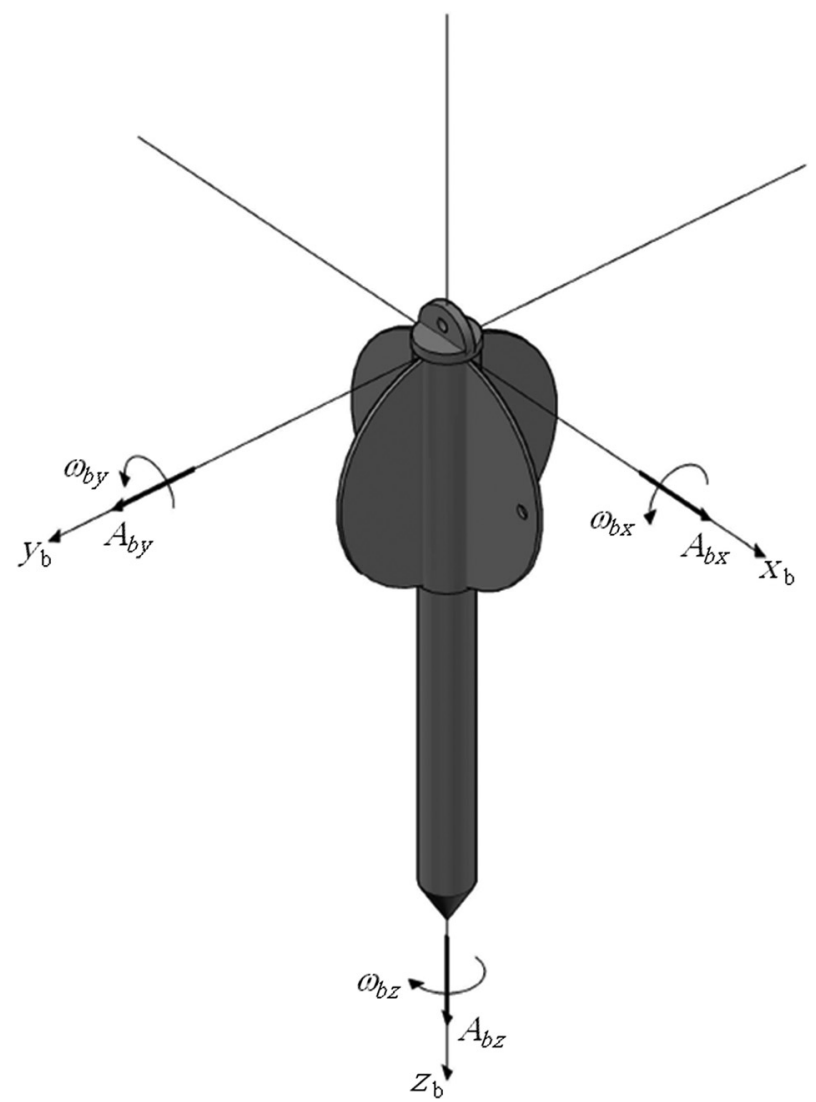

\section{Interpretation of IMU}

\section{Measurements}

As the body frame is not fixed in space, it is necessary to define an inertial frame, defined here and used in this paper, as a local fixed reference frame, with the $z$-axis aligned in the direction of the Earth's gravitational vector, and with undefined orthogonal $x$ - and $y$-axes, that are fixed at their orientation at the start of each test. If the projectile pitches and/or rolls while in motion, the body frame will move out of alignment with the inertial frame of reference and the rotation rates $\omega_{b x}, \omega_{b y}$, and $\omega_{b z}$ and accelerations $A_{b x}, A_{b y}$, and $A_{b z}$ measured by the IMU will not be coincident with the inertial frame (see Fig. 7). As a consequence gravitational acceleration $g$, and linear acceleration $a$ (required for velocity and translation calculations as described later), components cannot be distinguished from the accelerometer measurements. Hence the IMU measurements were "transformed" from the body frame to the inertial frame. This was accomplished using transformation matrices as described in the following sections.

\section{ROTATION}

The body frame rotation rates $\omega_{b x}, \omega_{b y}$, and $\omega_{b z}$ were transformed from the body frame to the inertial frame to correspond
FIG. 7 Body and inertial frames of reference.

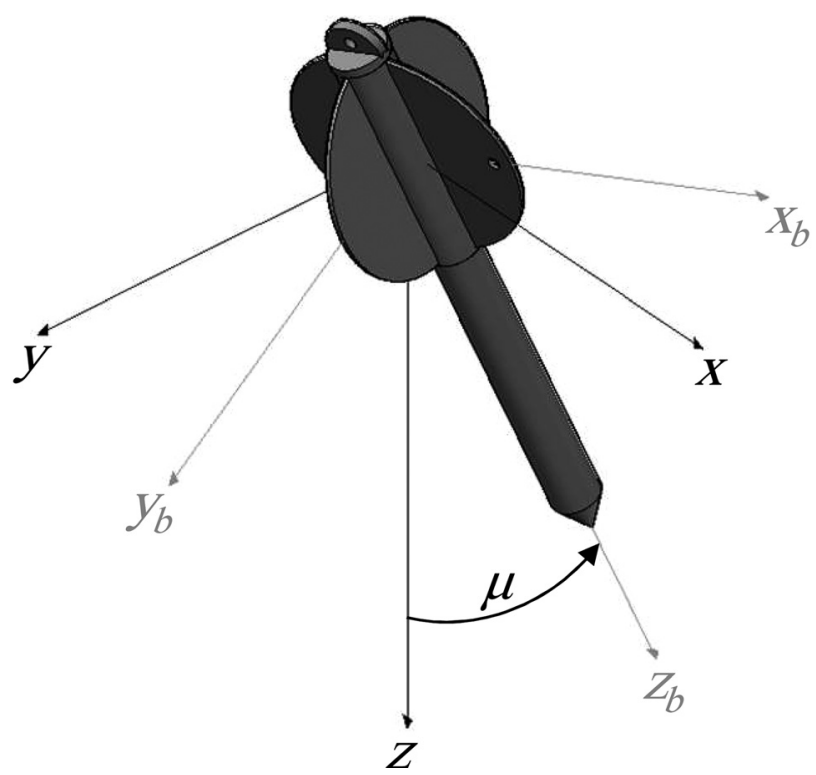

with rotation rates about the inertial frame $\omega_{x}, \omega_{y}$, and $\omega_{z}$ using an angular velocity transformation matrix (AVTM), $T_{b}^{i}$ (Fossen 2011):

$$
\begin{gathered}
\left(\begin{array}{c}
\omega_{x} \\
\omega_{y} \\
\omega_{z}
\end{array}\right)=T_{b}^{i}\left(\begin{array}{c}
\omega_{b x} \\
\omega_{b y} \\
\omega_{b z}
\end{array}\right) \\
T_{b}^{i}=\left(\begin{array}{ccc}
1 & \sin \left(\phi_{b}\right) \tan \left(\theta_{b}\right) & \cos \left(\phi_{b}\right) \tan \left(\theta_{b}\right) \\
0 & \cos \left(\phi_{b}\right) & -\sin \left(\phi_{b}\right) \\
0 & \sin \left(\phi_{b}\right) / \cos \left(\theta_{b}\right) & \cos \left(\phi_{b}\right) / \cos \left(\theta_{b}\right)
\end{array}\right)
\end{gathered}
$$

where:

$\phi_{b}$ and $\theta_{b}=$ the current rotation angles about the body frame axes $x_{b}$ and $y_{b}$, respectively, established from numerical integration of $\omega_{b x}$ and $\omega_{b y}$ :

$$
\begin{aligned}
& \phi_{b}(t)=\phi_{b 0}+\int_{0}^{t} \omega_{b x}(t) d t \\
& \theta_{b}(t)=\theta_{b 0}+\int_{0}^{t} \omega_{b y}(t) d t
\end{aligned}
$$

Similarly, the rotation angle $\psi_{b}$ about the body frame axis $z_{b}$ was established by numerical integration of $\omega_{b x}$ :

$$
\psi_{b}(t)=\psi_{b 0}+\int_{0}^{t} \omega_{b z}(t) d t
$$

Numerical integration of the angular velocities $\omega_{x}, \omega_{y}$, and $\omega_{z}$ derived from the AVTM allowed the roll $\phi$, pitch $\theta$, and yaw $\psi$ rotations about the inertial frame axes $x, y$, and $z$, respectively (Euler angles) to be established: 


$$
\begin{aligned}
& \phi(t)=\phi_{0}+\int_{0}^{t} \omega_{x}(t) d t \\
& \theta(t)=\theta_{0}+\int_{0}^{t} \omega_{y}(t) d t \\
& \psi(t)=\psi_{0}+\int_{0}^{t} \omega_{z}(t) d t
\end{aligned}
$$

\section{ACCELERATION}

The accelerometer measurements $A_{b x}, A_{b y}$, and $A_{b z}$ were converted to accelerations coincident with the inertial frame $A_{x}, A_{y}$, and $A_{z}$ using a direction cosine matrix (DCM) $R_{b}^{i}$ (Nebot and Durrant-Whyte 1999; Jonkman 2007; King et al. 2008; Fossen 2011):

$$
\begin{gathered}
\left(\begin{array}{c}
A_{x} \\
A_{y} \\
A_{z}
\end{array}\right)=R_{b}^{i}\left(\begin{array}{c}
A_{b x} \\
A_{b y} \\
A_{b z}
\end{array}\right) \\
R_{b}^{i}=R_{z}(-\psi) R_{y}(-\theta) R_{x}(-\phi)
\end{gathered}
$$

The DCM relates the accelerations measured in the body frame to the inertial frame by considering three successive rotations of yaw $-\psi$, pitch $-\theta$, and roll $-\phi$ about the inertial frame axes $z, y$, and $x$, respectively. These rotations are represented by the yaw $R_{z}(-\psi)$, pitch $R_{y}(-\theta)$, and roll $R_{x}(-\phi)$ matrices that are used to rotate the measured acceleration vectors $A_{b x}, A_{b y}$, and $A_{b z}$ in Euclidean vector space:

$$
\begin{aligned}
& R_{z}(-\psi)=\left(\begin{array}{ccc}
\cos (-\psi) & \sin (-\psi) & 0 \\
-\sin (-\psi) & \cos (-\psi) & 0 \\
0 & 0 & 1
\end{array}\right) \\
& R_{y}(-\theta)=\left(\begin{array}{ccc}
\cos (-\theta) & 0 & -\sin (-\theta) \\
0 & 1 & 0 \\
\sin (-\theta) & 0 & \cos (-\theta)
\end{array}\right) \\
& R_{x}(-\phi)=\left(\begin{array}{ccc}
1 & 0 & 0 \\
0 & \cos (-\phi) & \sin (-\phi) \\
0 & -\sin (-\phi) & \cos (-\phi)
\end{array}\right)
\end{aligned}
$$

Multiplication of the $R_{z}(-\psi), R_{y}(-\theta)$, and $R_{x}(-\phi)$ rotation matrices gives the DCM:

$$
R_{b}^{i}=\left(\begin{array}{ccc}
\cos (-\psi) \cos (-\theta) & \cos (-\phi) \sin (-\psi)+\cos (-\psi) \sin (-\phi) \sin (-\theta) & \sin (-\phi) \sin (-\psi)-\cos (-\phi) \cos (-\psi) \sin (-\theta) \\
-\cos (-\theta) \sin (-\psi) & \cos (-\psi) \cos (-\phi)-\sin (-\theta) \sin (-\phi) \sin (-\psi) & \cos (-\psi) \sin (-\phi)+\cos (-\phi) \sin (-\psi) \sin (-\theta) \\
\sin (-\theta) & -\cos (-\theta) \sin (-\phi) & \cos (-\theta) \cos (-\phi)
\end{array}\right)
$$

The linear accelerations coincident with the inertial frame $a_{x}, a_{y}$, and $a_{z}$ were derived from the transformed accelerometer measurements $A_{x}, A_{y}$, and $A_{z}\left(A_{z}\right.$ is a negative output, i.e., when the projectile is at rest, $a_{z}=A_{z}+g=0$ ) using the following expression (Stovall 1997; Noureldin et al. 2012):

$$
\left(\begin{array}{l}
a_{x} \\
a_{y} \\
a_{z}
\end{array}\right)=\left(\begin{array}{l}
A_{x} \\
A_{y} \\
A_{z}
\end{array}\right)+\left(\begin{array}{l}
0 \\
0 \\
g
\end{array}\right)
$$

The resultant linear acceleration, $a$ (acceleration in the direction of motion), was calculated as:

$$
a=\sqrt{A_{x}^{2}+A_{y}^{2}+A_{z}^{2}}-g
$$

\section{VELOCITY AND DISTANCE}

The linear accelerations corresponding to the inertial frame $a_{x}$, $a_{y}$, and $a_{z}$ were numerically integrated to establish the projectile velocities coincident with the inertial frame $v_{x}, v_{y}$, and $v_{z}$ during free fall in the water column and embedment in the soil:

$$
v_{x}(t)=v_{x 0}+\int_{0}^{t} a_{x}(t) d t
$$

$$
\begin{aligned}
& v_{y}(t)=v_{y 0}+\int_{0}^{t} a_{y}(t) d t \\
& v_{z}(t)=v_{z 0}+\int_{0}^{t} a_{z}(t) d t
\end{aligned}
$$

The resultant projectile velocity $v$, was calculated using the following expression:

$$
v=\sqrt{v_{x}^{2}+v_{y}^{2}+v_{z}^{2}}
$$

which was numerically integrated to establish the distance traveled by the projectile along its trajectory $s$ :

$$
s(t)=s_{0}+\int_{0}^{t} v(t) d t
$$

The distance traveled by the projectile along the inertial $z$-axis $s_{z}$ (required to calculate the vertical embedment depth of the projectile relative to the soil surface, $z_{e}$ ), was established by numerically integrating the vertical velocity $v_{z}$ :

$$
s_{z}(t)=s_{z 0}+\int_{0}^{t} v_{z}(t) d t
$$




\section{TILT ANGLES}

Following dynamic penetration the projectile is at rest in the soil and has no linear acceleration. Under these conditions the accelerometer measurements can be used to derive the final pitch $\phi_{\text {acc }}$, roll $\theta_{\text {acc }}$ (coincident with the inertial frame) and resultant tilt $\mu$ (tilt relative to Earth's gravitational vector; see Fig. 7) angles using the following expressions (King et al. 2008; Stephan et al. 2012):

$$
\begin{gathered}
\phi_{\mathrm{acc}}=\sin ^{-1}\left(\frac{A_{b y}}{g}\right) \\
\theta_{\mathrm{acc}}=\sin ^{-1}\left(\frac{A_{b x}}{g}\right) \\
\mu=\cos ^{-1}\left(\frac{A_{b z}}{g}\right)
\end{gathered}
$$

\section{Test Sites and Soil Properties}

The IMU performance has been examined using projectile data from two sites. The DEPLA data considered here relate to tests conducted in the Firth of Clyde, which is located off the West coast of Scotland between the mainland and the Isle of Cumbrae. The DPA and IFFS data are from tests conducted in Lower Lough Erne, which is an inland lake located in County Fermanagh, Northern Ireland. At Lough Erne the water depths at the test locations varied between 3 and $20 \mathrm{~m}$, whereas at the Firth of Clyde test locations the water depth was typically $50 \mathrm{~m}$. Both test locations are shown in Fig. 8.

The seabed at the DEPLA test locations in the Firth of Clyde is very soft with moisture content in the range $50 \%$ to $100 \%$ (close to the liquid limit). Consistency limits plot above or on the A-line on the Casagrande plasticity chart, indicating a clay of intermediate to high plasticity. The unit weight increases from about $\gamma=14 \mathrm{kN} / \mathrm{m}^{3}$ at the mudline to about $\gamma=18 \mathrm{kN} / \mathrm{m}^{3}$ at about $3.5 \mathrm{~m}$ (limit of the sampling depth). Fig. 9 (a) shows profiles of undrained shear strength $s_{u}$, with depth derived from piezocone and piezoball tests, and calibrated using lab shear vane data and fall cone tests, to give piezocone bearing factors $N_{k t}=17.8\left(5 \mathrm{~cm}^{2}\right.$ cone $)$ and $N_{k t}=16.9\left(10 \mathrm{~cm}^{2}\right.$ cone $)$, and piezoball bearing factors $N_{\text {ball }}=11.5\left(50 \mathrm{~cm}^{2}\right.$ ball $)$ and $N_{\text {ball }}=12.2\left(100 \mathrm{~cm}^{2}\right.$ ball $)$. The $s_{u}$ profile is best idealized as $s_{u}(\mathrm{kPa})=2+2.8 z$ over the upper $z=5 \mathrm{~m}$ of the penetration profile, which is the depth of interest for the DEPLA tests. The ratio of remolded to intact soil resistance is in the range 0.19 to 0.33 as assessed from piezoball cyclic remolding tests. This range is similar, but not identical to the range of soil sensitivity, as the bearing factor for remolded soil is greater than for intact soil (Yafrate et al. 2009; Zhou and Randolph 2009).
FIG. 8

Location of test sites.

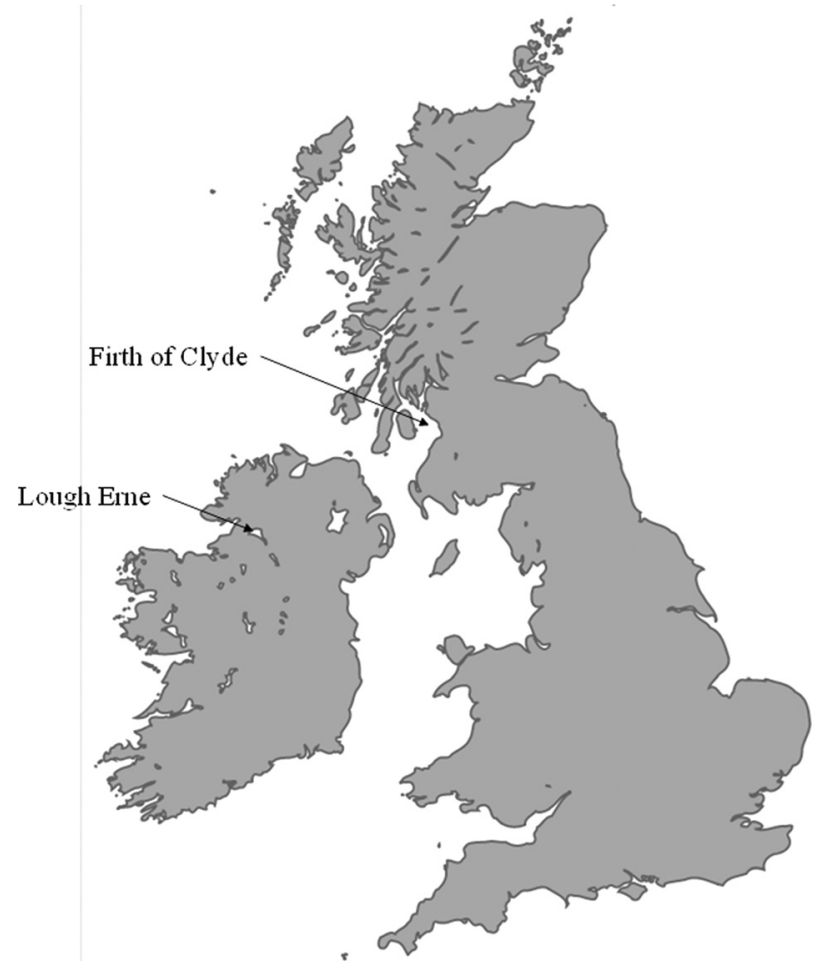

The Lough Erne lakebed is very soft clay with moisture contents in the range $270 \%$ to $520 \%$, typically about 1.5 times the liquid limit. The measured unit weight of the Lough Erne clay is only marginally higher than water at $\gamma=10.8 \mathrm{kN} / \mathrm{m}^{3}$. This is considered to be because of the very high proportion of diatoms that are evident from scanning electron microscopic images of the soil (e.g., see Colreavy et al. 2012) and which have an enormous capacity to hold water in the intraskeletal pore space (Tanaka and Locat 1999). Colreavy et al. (2012) report data from piezoball penetration tests (using a $100 \mathrm{~cm}^{2}$ ball) at the Lough Erne site to depths of up to $8 \mathrm{~m}$. Fig. $\mathbf{9 ( b )}$ shows $s_{u}$ profiles with depth, obtained from the net penetration resistance using $N_{\text {ball }}=8.6$, calibrated using in situ shear vane data. The undrained shear strength profile is best idealized over the depth of interest ( 0 to $2.2 \mathrm{~m}$ ) as $s_{u}(\mathrm{kPa})=1.5 z$. Piezoball cyclic remolding tests show that the ratio of remolded to intact soil resistance is in the narrow range 0.4 to 0.5 , indicating a low sensitivity soil.

\section{TEST PROCEDURE}

Testing was conducted using the RV Aora, a $22 \mathrm{~m}$ research and survey vessel in Firth of Clyde (Fig. 10(a)) and either a fixed vessel berthing jetty or a 15-m self-propelled barge (Fig. 10(b)) in Lough Erne. The self-propelled barge was equipped with a 13-ton winch and a 2-ton crane, whereas the RV Aora was equipped with several winches and an 8-ton crane. The testing 
FIG. 9

Undrained shear strength profiles: (a) Firth of Clyde and (b) Lough Erne.
Undrained shear strength, $S_{\mathrm{u}}(\mathrm{kPa})$

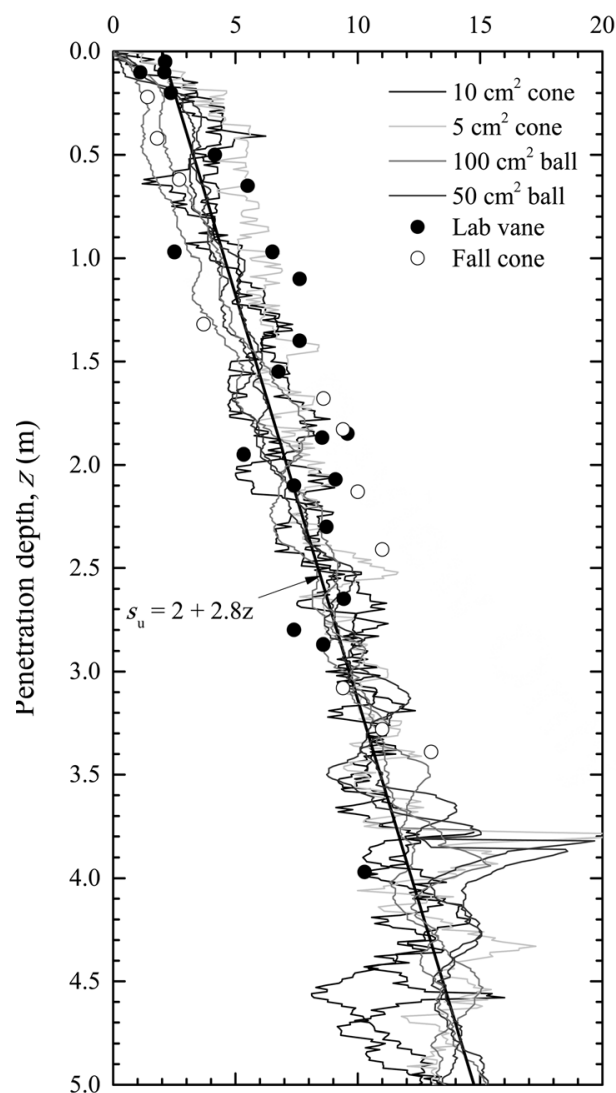

(a)

(b)
Undrained shear strength, $s_{u}(\mathrm{kPa})$

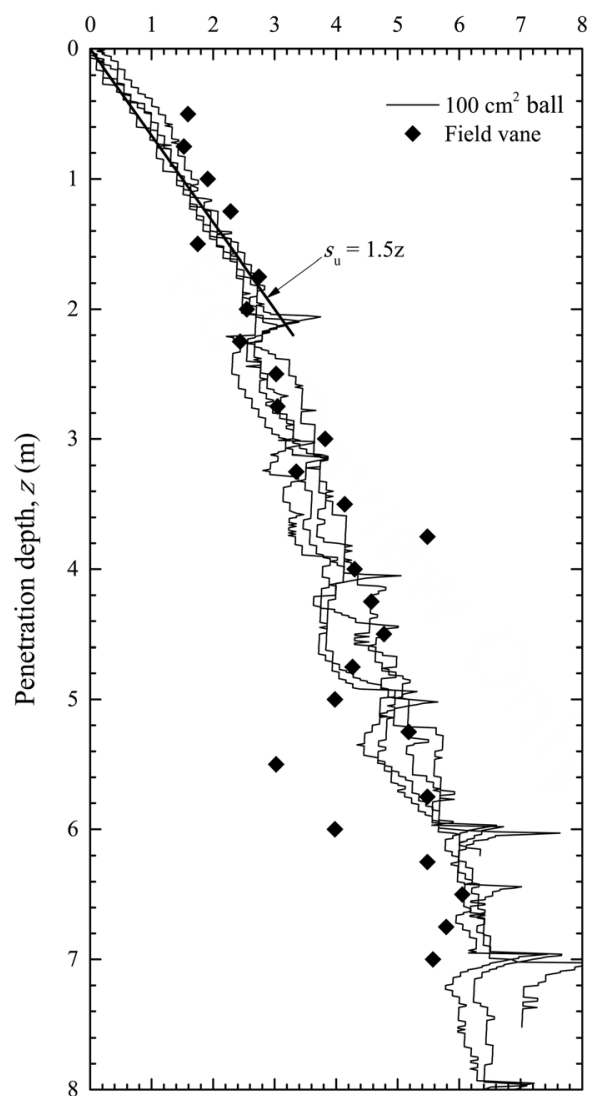

\section{ROTATION}

Rate gyroscopes are subject to an error known as bias drift where the zero rate output drifts over time (Sharma 2007). However, the duration of a projectile drop never exceeded $6.5 \mathrm{~s}$, which is too short for any measurable bias drift to accumulate. This was confirmed by comparing the zero rate outputs before the drop when the anchor was hanging in the water with the zero rate outputs after the drop when the anchor was at rest in the soil. No change was observed for any test.

Fig. 13 shows typical rotation profiles during free fall in water and embedment in the lakebed for each of the three projectiles, released from drop heights of $17.69 \mathrm{~m}$ (DEPLA), $5.95 \mathrm{~m}$ (IFFS), and $3 \mathrm{~m}$ (DPA). In Fig. 13, $\phi_{\mathrm{acc}}$ and $\theta_{\mathrm{acc}}$ are rotations relative to the inertial frame deduced from the horizontally orientated $y$ - and $x$-axes accelerometers using Eqs 23 and 24, $\phi_{b}$, $\theta_{b}$, and $\psi_{b}$ are rotations about the body frame axes $x_{b}, y_{b}$, and $z_{b}$ established using Eqs 3, 4, and 5, and $\phi, \theta$, and $\psi$ are the pitch, roll, and yaw rotations about the inertial frame axes $x, y$, and $z$ derived using Eqs 6, 7, and 8.

In Fig. 13(a), prior to release (time, $t=0$ to $1.1 \mathrm{~s}$ ) the DEPLA was swaying in the water, suspended from the installation line, during which time rotations derived from the 
FIG. 10 (a) RV Aora and (b) self-propelled barge.
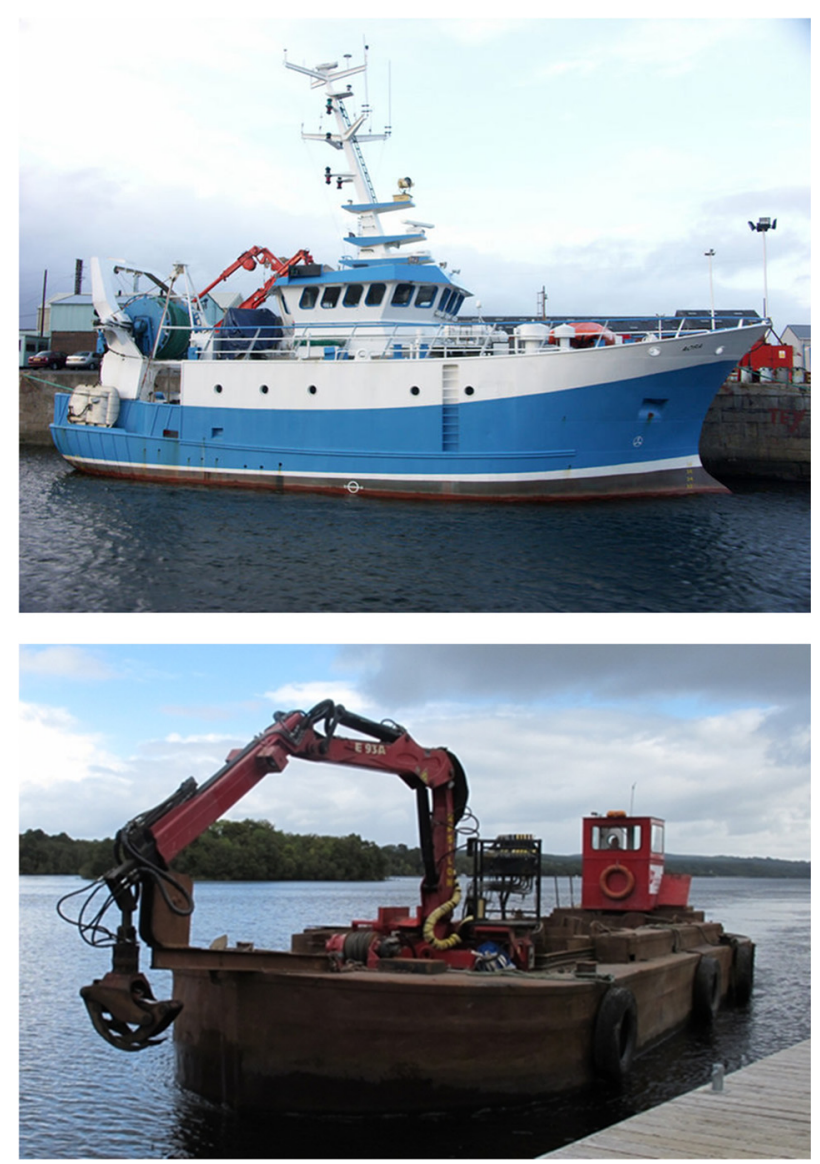

accelerometer measurements ( $\phi_{\text {acc }}$ and $\left.\theta_{\text {acc }}\right)$ and from the gyroscope measurements $\left(\phi_{b}\right.$ and $\left.\theta_{b}\right)$ were in broad agreement. During free fall ( $t=1.1 \mathrm{~s}$ to $3.59 \mathrm{~s})$ rotations can only be interpreted from the gyroscope measurements as the accelerometer measurements include both acceleration and rotation components. The gyroscope measurements indicate that rotations reached $\phi_{b}=17.3^{\circ}$ and $\theta_{b}=-8.3^{\circ}$ when the anchor came to rest in the lakebed at $t=4.2 \mathrm{~s}$. There is a discrepancy of $\Delta \phi=1.7^{\circ}$ and $\Delta \theta=3.1^{\circ}$ between the accelerometer and gyroscope measurements while the anchor is at rest. However, when the anchor was at rest in the soil the "transformed" rotations derived from the gyroscope measurements ( $\phi$ and $\theta$ ) were in good agreement with rotations derived from the accelerometer measurements, as both were coincident with the inertial frame of reference.

Fig. 13(b) shows that the IFFS rotated about all three axes during freefall in water and penetration in soil. Indeed, the nonzero $\psi_{b}$ and $\psi$ response started while the IFFS was hanging in water, indicating that the IFFS started to spin before it was released. After the IFFS came to rest in the soil there is a discrepancy of $\Delta \phi=4.1^{\circ}$ and $\Delta \theta=2.8^{\circ}$ between the final accelerometer and gyroscope measurements. As with the DEPLA test, the transformed rotations derived from the gyroscope
FIG. 11 DEPLA field test procedure.
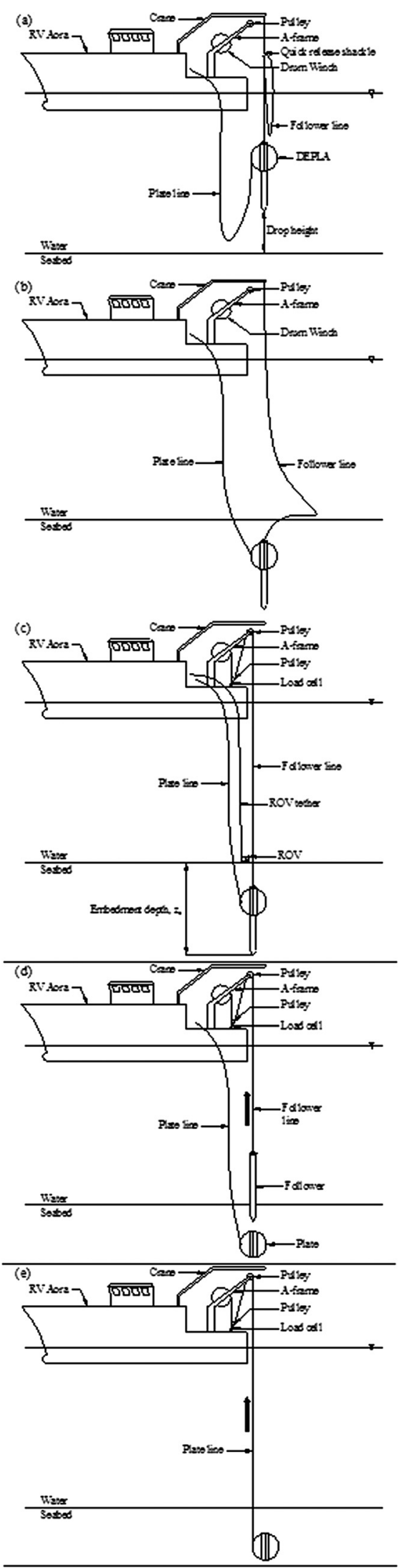
FIG. 12 Image capture from ROV camera showing the follower retrieval line at the seabed.

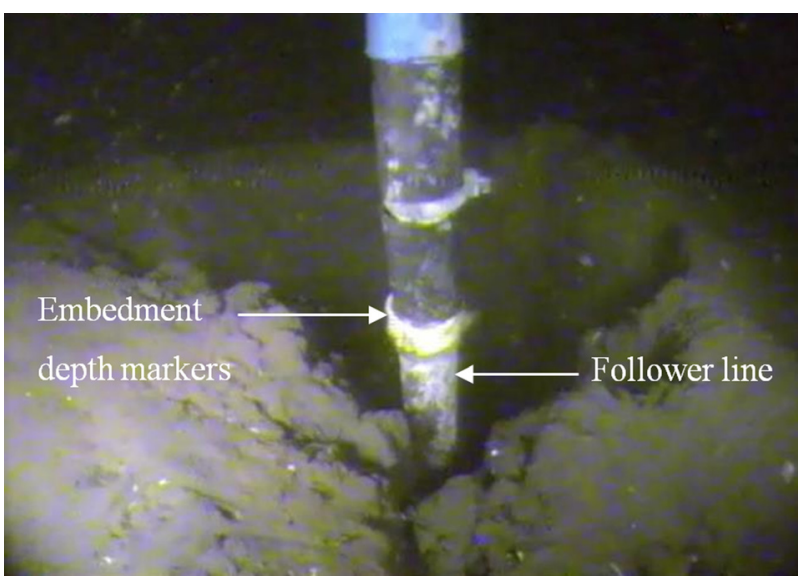

measurements were in good agreement with rotations derived from the accelerometer measurements. This highlights the importance of using the AVTM to transform the angular velocities measured by the gyroscope from the body frame to the inertial frame to establish rotations that relate to the inertial frame.

In contrast, rotations measured during the DPA free fall and embedment phases (Fig. 13(c)) were much lower than from the DEPLA and IFFS tests. Indeed, the rotation appears to have only occurred before release (because of swaying and spinning in water) and at the start of the free fall phase, indicating that the DPA tends to self-correct and become hydrodynamically stable during free fall in water. As such the misalignment between the body frame of the IMU (and hence the anchor) and the inertial frame of reference in this case was negligible, with no discernible differences in the rotations derived from the final accelerometer and gyroscope measurements when the anchor came to rest in the soil. Hence, transformation of rotations between the body frame and the inertial frame may not be warranted in cases where the rotations are relatively small.

\section{ACCELERATION}

Fig. 14 shows acceleration profiles for the same tests as shown in Fig. 13. In Fig. 14, $A_{b x}, A_{b y}$, and $A_{b z}$ are the accelerometer measurements and $A_{x}, A_{\mathrm{y}}$, and $A_{z}$ are the transformed accelerometer measurements that are coincident with the inertial frame (i.e., $A_{z}$ is the acceleration measurement in the direction of gravity). In Fig. 14(a), the DEPLA was initially hanging in the water experiencing only gravitational acceleration with $A_{x}=0 \quad\left(a_{x}=0\right)$, $A_{y}=0\left(a_{y}=0\right)$, and $A_{z}=-9.81 \mathrm{~m} / \mathrm{s}^{2}$ (i.e., $a_{z}=0$, refer to $\mathrm{Eq}$ 15). Following release at $t=1.1 \mathrm{~s}$, the anchor began to free fall in water with an abrupt change in $A_{z}$ to $-0.81 \mathrm{~m} / \mathrm{s}^{2}\left(a_{z}=9 \mathrm{~m} /\right.$ $\mathrm{s}^{2}$ ). From $t=1.1$ to $3.59 \mathrm{~s}$, the anchor was in free fall through water and $A_{z}$ (and, hence, $a_{z}$ ) steadily reduced as the fluid drag
FIG. 13 Projectile rotations during free fall through water and soil penetration: (a) DEPLA, (b) IFFS, and (c) DPA.

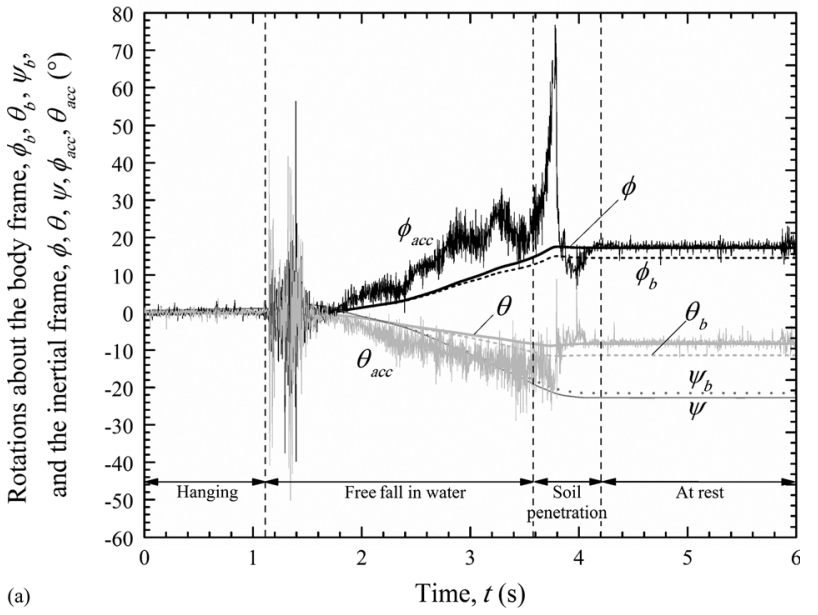

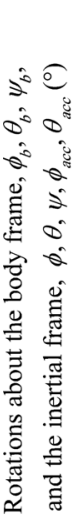
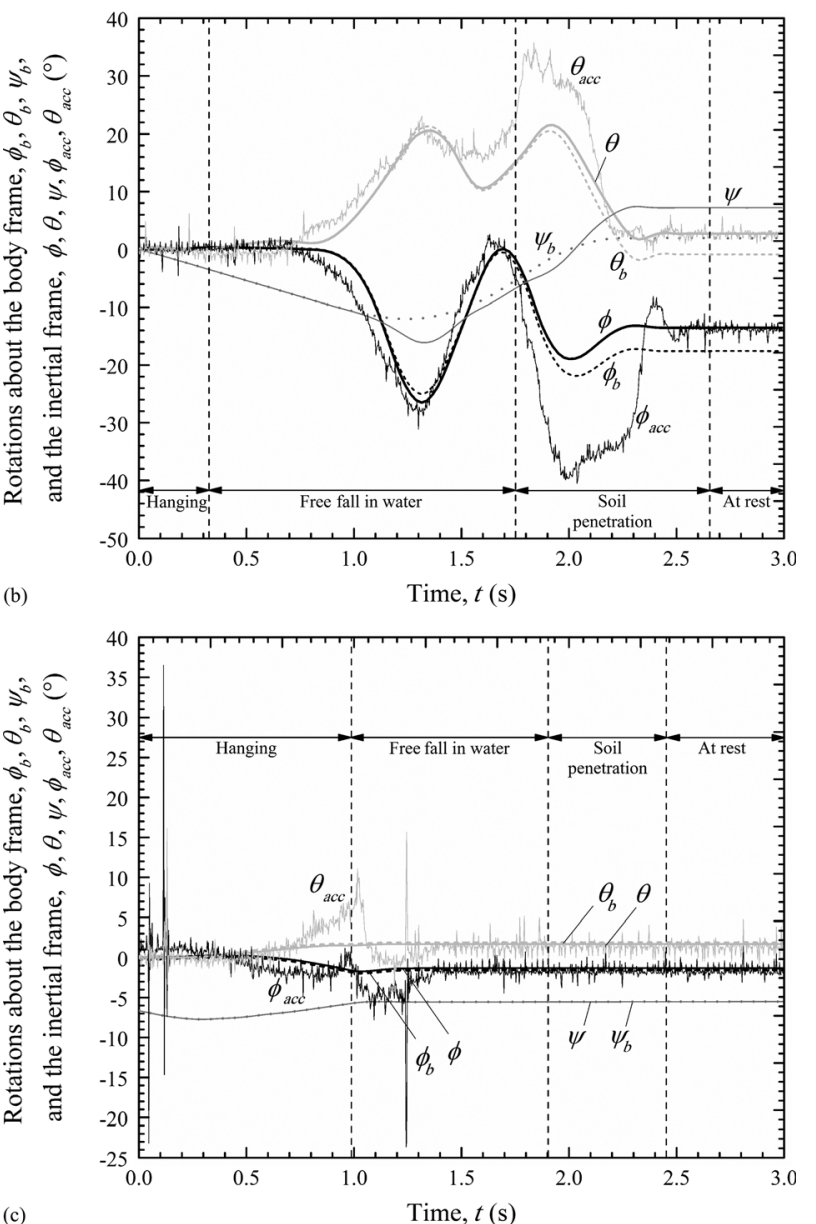

resistance increased with increasing anchor velocity. Impact with the mudline occurred at $t=3.59 \mathrm{~s}$ and is characterized by a rapid deceleration to a maximum value of approximately $A_{z}=-41.6 \mathrm{~m} / \mathrm{s}^{2}\left(a_{z}=-3.2 \mathrm{~g}=-31.8 \mathrm{~m} / \mathrm{s}^{2}\right)$. The anchor came to rest at $t=4.2 \mathrm{~s}$ before rebounding slightly. This rebound has been reported in other studies involving free-fall objects (e.g., 
FIG. 14 Projectile accelerations during free fall through water and soil penetration: (a) DEPLA, (b) IFFS, and (c) DPA.

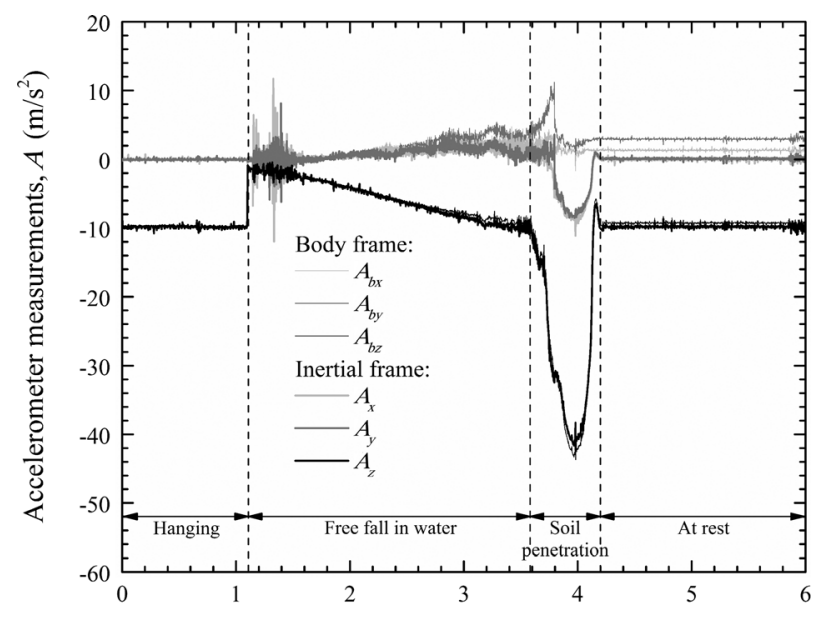

(a)

Time, $t(\mathrm{~s})$
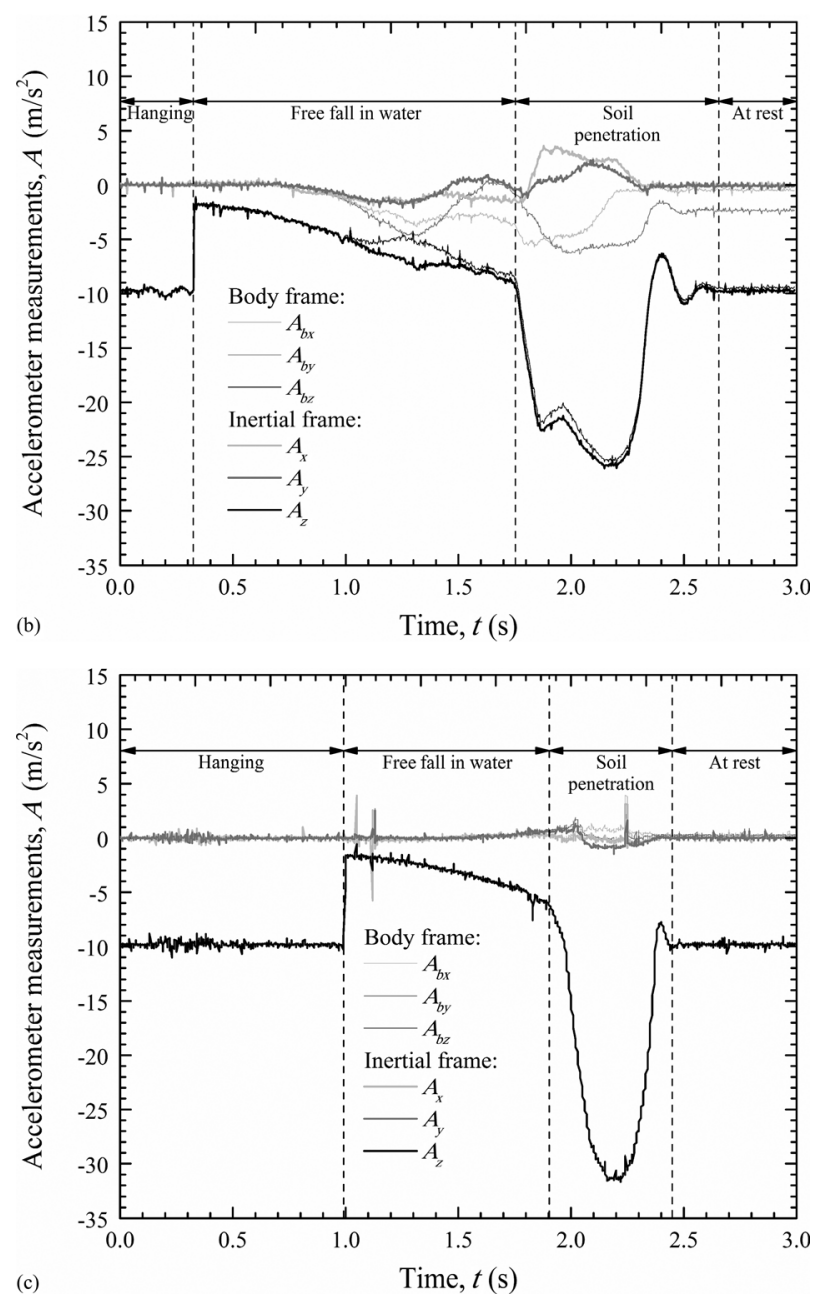

Dayal and Allen 1973; Chow and Airey 2010; Morton and O'Loughlin 2012; O'Loughlin et al. 2014), and is attributed to elastic rebound of the soil. The importance of transforming the measured accelerations to the inertial frame using the DCM is evident from the soil penetration phase where the magnitude of the peak inertial frame deceleration $A_{z}$ is $3.7 \%$ lower than the peak body frame deceleration $A_{b z}$. Furthermore, when the anchor was at rest the inertial frame accelerations $A_{x}$ and $A_{y}$, sensibly returned to zero and $A_{z}=-9.81 \mathrm{~m} / \mathrm{s}^{2}\left(a_{z}=0\right)$ in the absence of linear acceleration, whereas the body frame accelerations, $A_{b x}$ and $A_{b y}$ are non-zero, and $A_{b z} \neq-9.81 \mathrm{~m} / \mathrm{s}^{2}$ because of anchor rotations causing misalignment between the body and inertial frames.

The acceleration response of the IFFS (Fig. 14(b)) is broadly similar to that of the DEPLA, with the expected change in acceleration upon release and the subsequent reduction in acceleration because of increasing fluid drag resistance. Accelerations also reduce markedly upon impact with the soil surface, although the absolute deceleration is lower than for the DEPLA because of the lower soil strength at this site. The sudden reduction in the accelerations along the $z$-axis during penetration in soil (evident in both the body frame and the inertial frame accelerations) is considered to be because of changes in the soil flow regime. This influences the magnitude of the drag resistance that dominates at these very shallow embedment depths in very soft soil and at high penetration velocities (Morton et al. 2015).

Fig. 14(c) shows the acceleration response for the DPA test. The response is qualitatively similar to those shown in Fig. 14(a) and $\mathbf{1 4 ( b )}$ for the DEPLA and the IFFS, respectively, although there is negligible difference between the body frame accelerations and the transformed inertial frame accelerations as rotations were relatively small for this test.

\section{VELOCITY PROFILES}

Fig. 15 shows velocity profiles for free fall in water and embedment into soil for the three tests considered previously and shown in Figs. 13 and $\mathbf{1 4}$. The velocity $v_{z}$, and distance $s_{z}$ (i.e., depth) relative to the inertial frame were established using Eqs 19 and 20. The velocity $v_{b z}$, and distance $z_{b z}$, were also derived from Eqs 19 and 20, albeit with $a_{b z}=A_{b z}+g$, instead of $a_{z}$ and $A_{z} \cdot v_{b z}$ and $z_{b z}$ represent the values that would otherwise be used if the IMU measurements were not corrected using the AVTM and DCM. The importance of implementing the transformation matrices is demonstrated in Fig. 15(a), where the final embedment depth and impact velocity of the DEPLA are overestimated by $12 \%$ and $7 \%$, respectively. This would correspond to an over prediction of the local undrained shear strength (and hence capacity) at the mid-height of the DEPLA plate (following installation but prior to keying) of $17 \%$ based on the final tip embedment of $z_{e}=3.31 \mathrm{~m}$ and the idealized strength profile, $s_{u}(\mathrm{kPa})=2+2.8 z$. Fig. 15 (b) indicates that the embedment depth and impact velocity of the IFFS are over predicted by $27 \%$ and $10 \%$, respectively. The over prediction for the IFFS is higher than for the DEPLA as the IFFS rotations are higher (i.e., greater misalignment between the body- and inertial frames). 
FIG. 15 Projectile velocity profiles corresponding to free fall through water and soil penetration: (a) DEPLA, (b) IFFS, and (c) DPA.

Velocity, $v_{b z}$ and $v_{z}(\mathrm{~m} / \mathrm{s})$

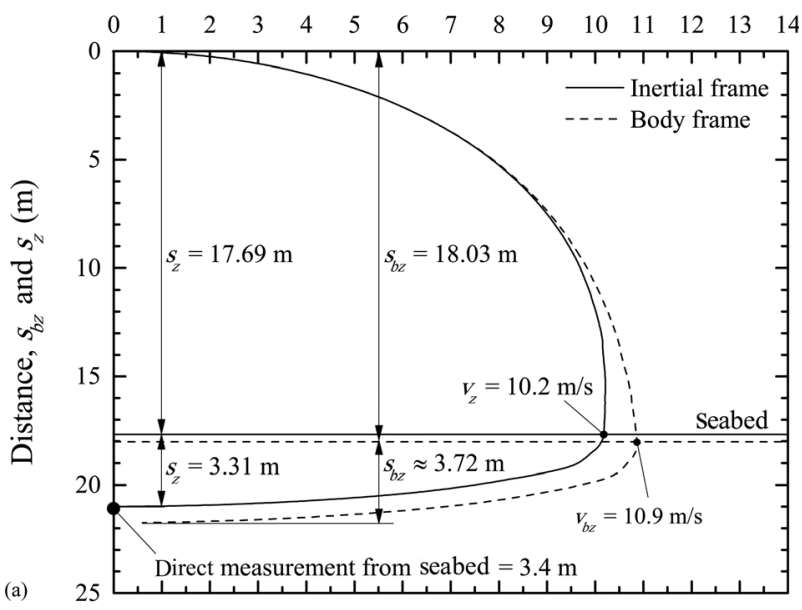

Velocity, $v_{b z}$ and $v_{z}(\mathrm{~m} / \mathrm{s})$

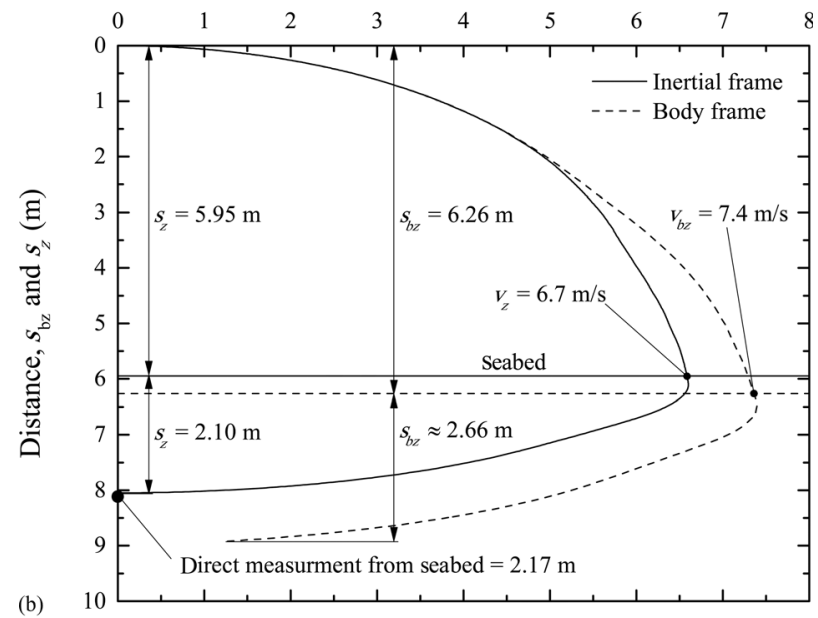

Velocity, $v_{b z}$ and $v_{z}(\mathrm{~m} / \mathrm{s})$

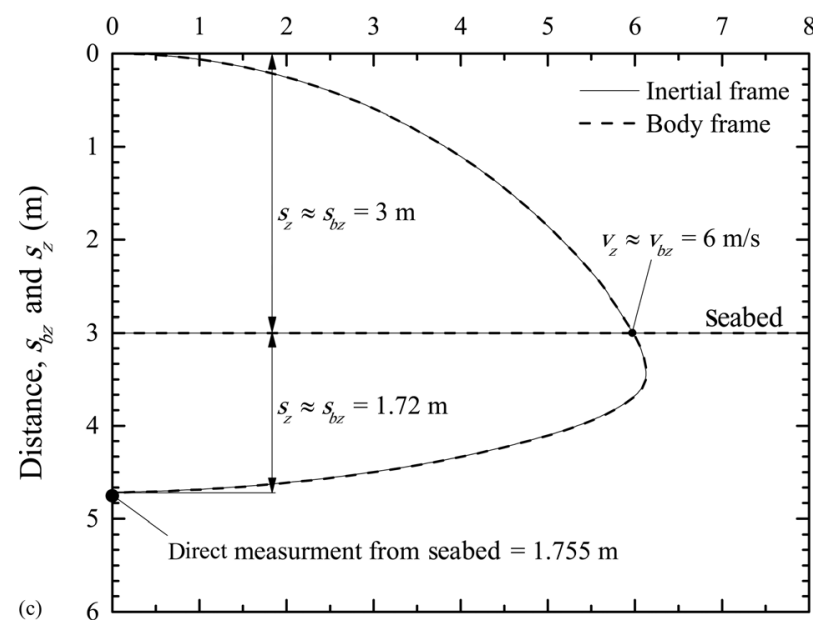

FIG. 16 Comparison of IMU derived displacement measurements with those obtained using a draw wire sensor.

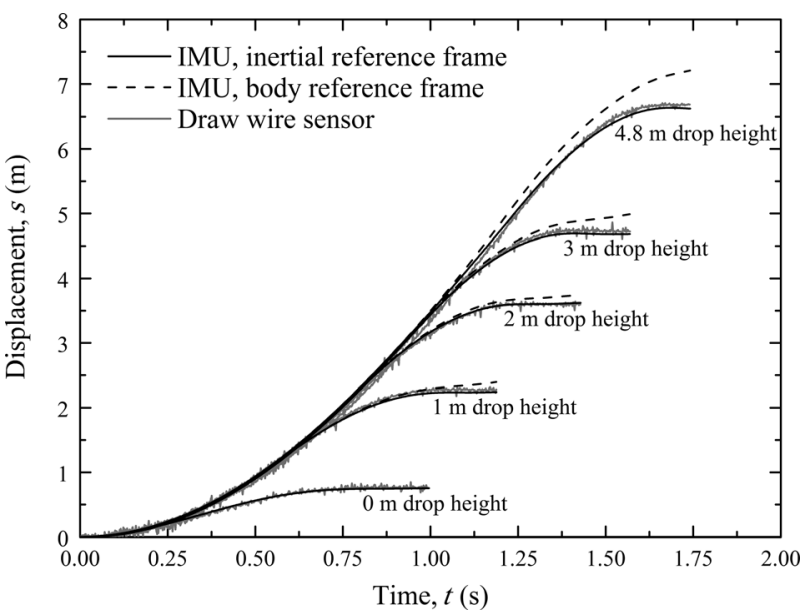

Fig. 15(a) and 15(b) also show that the velocity $v_{b z}$, established from the integration of the body frame "linear" acceleration $a_{b z}$, does not return to zero despite motion having ceased. This is because the body-frame acceleration measurement $A_{b z}$ (from which $a_{b z}$ is derived) is not coincident with the inertial frame and does not return to zero following installation (i.e., $A_{b z}>-9.81 \mathrm{~m} / \mathrm{s}^{2}$ ). The DPA body frame and inertial frame velocity profiles (Fig. 15(c)) are in excellent agreement as the rotations are relatively low and the misalignment between the body frame and inertial frame is negligible. Also shown on Fig. 15 are direct measurements of the final embedment depths based on mudline observations of markings on the retrieval line using a ROV in Firth of Clyde and an underwater drop camera in Lough Erne. Final embedment depths derived from the IMU data are within $3.3 \%$ of the direct measurements, with differences of $0.09 \mathrm{~m}$ (DEPLA), $0.06 \mathrm{~m}$ (IFFS), and $0.035 \mathrm{~m}$ (DPA). However, the direct measurements are simply to confirm the lack of any gross error in the analysis, and have a much lower accuracy than is possible from the IMU data. A more rigorous verification of the IMU derived measurements was undertaken for a number of tests as described in the following section.

\section{VERIFICATION OF THE IMU-DERIVED MEASUREMENTS}

Independent verification of the IMU-derived measurements of the projectile displacement (Eq 22) was obtained by comparison with those obtained from a draw wire sensor (also known as a string potentiometer) with a $10-\mathrm{m}$ measurement range. The draw wire sensor was connected between a fixed point on the deployment platform and the free-falling projectile (i.e., in parallel with the deployment and retrieval line), and the data acquired using an independent 24-bit data-acquisition system. Five tests were undertaken using the IFFS projectile released from 0 to $4.8 \mathrm{~m}$ above the lakebed. 
FIG. 17 DEPLA velocity profile derived from the IMU data measured at the Firth of Clyde test site and corresponding theoretical profiles.

\section{Resultant velocity, $v(\mathrm{~m} / \mathrm{s})$}

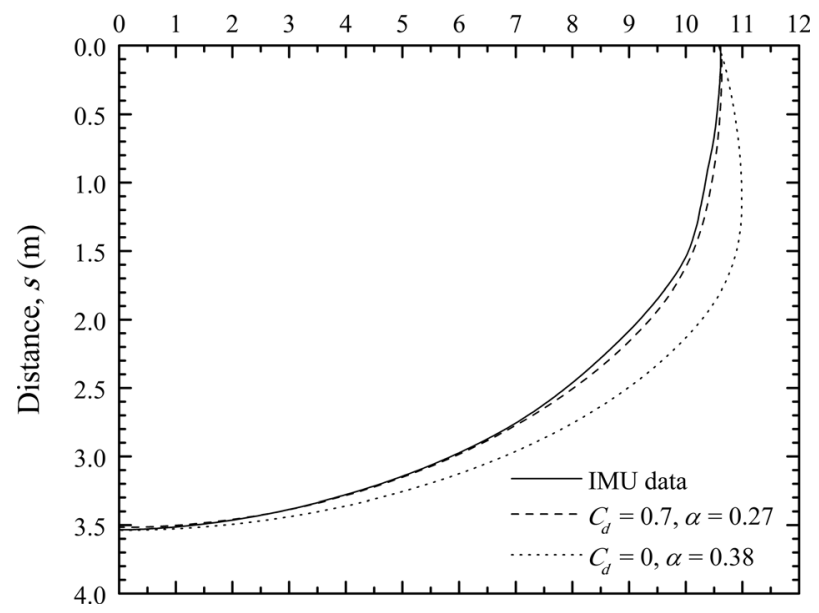

Comparisons of displacements derived from the IMU measurements and the draw wire sensor data are provided in Fig. 16. The IMU-derived displacements are shown both using the body reference frame and the inertial reference frame. This shows that the inertial frame-derived displacements correctly remain constant when the projectile comes to rest in the soil. In contrast, the body frame-derived displacements continue to increase as the resultant linear acceleration, $a$, has not returned to zero because of the rotation of the body (see also Fig. 15). Importantly, excellent agreement is apparent between the inertial frame displacements and those measured by the draw wire sensor (within $1 \%$ of the measurement range), providing verification of the analysis approach outlined here.

\section{EXAMPLE APPLICATION OF PROJECTILE IMU DATA}

For the projectiles considered in the previous section, understanding the soil-structure interaction at such high strain rates is crucial for predictive tools that calculate the final embedment depth of the anchors (DEPLA and DPA; e.g., O'Loughlin et al. 2013 b) or estimate the undrained shear strength based on the interpreted inertial frame accelerations (IFFS; O'Loughlin et al. 2014; Morton et al. 2015). This is because those strain rates are up to seven orders of magnitude higher than used for strength determination in a standard laboratory element test. It follows that motion data such as those presented in Figs. 13 and $\mathbf{1 4}$ play an important role in the validation and calibration of such predictive models. An example comparison is provided in Fig. 17 for the DEPLA, where the predictions are based on an analytical model described in brief here, but in more detail by O'Loughlin et al. (2013b). The model formulates conventional end bearing and frictional resistance acting on the anchor during penetration in a manner similar to suction caisson or pile installation, but scales these resistances to account for the well-known dependence of undrained shear strength on strain rate (Casagrande and Wilson 1951; Graham et al. 1983; Sheahan et al. 1996), while also accounting for drag resistance and the buoyant weight of the displaced soil. Consideration of these resistance components leads to the following governing equation:

$$
m \frac{d^{2} s}{d t^{2}}=W_{s}-F_{b}-R_{f}\left(F_{\text {frict }}+F_{\text {bear }}\right)-F_{d}
$$

where:

$m=$ the anchor mass,

$s=$ the distance traveled by the projectile,

$t=$ time,

$W_{s}=$ the submerged weight of the anchor in water,

$F_{\text {frict }}=$ frictional resistance,

$F_{\text {bear }}=$ bearing resistance,

$F_{b}=$ the buoyant weight of the displaced soil, and

$F_{d}=$ drag resistance, formulated as:

$$
F_{d}=\frac{1}{2} C_{d} \rho_{s} A_{p} v^{2}
$$

where:

$\rho_{s}=$ the submerged density of the soil,

$C_{d}=$ the drag coefficient,

$A_{p}=$ anchor projected (frontal) area, and

$v=$ the instantaneous resultant anchor velocity.

The inclusion of drag resistance, $F_{d}$, is essential in situations where (non-Newtonian) very soft fluidized soil is encountered at the surface of the seabed, and has been shown to be important for assessing loading from a submarine slide runout on a pipeline (Boukpeti et al. 2012; Randolph and White 2012; Sahdi et al. 2014). O'Loughlin et al. (2013b) and Blake and O'Loughlin (2015) further showed that drag is the dominant resistance acting on a dynamically installed anchor in normally consolidated clay during initial embedment and typically to about $30 \%$ of the penetration.

Frictional and bearing resistances are formulated as

$$
\begin{aligned}
& F_{\text {frict }}=\alpha s_{u} A_{s} \\
& F_{\text {bear }}=N s_{u} A_{p}
\end{aligned}
$$

where:

$\alpha=$ an interface friction ratio (of limiting shear stress to undrained shear strength),

$A_{s}=$ anchor shaft area, $N$ is the bearing capacity factor for the projectile tip or fluke, and

$s_{u}=$ the undrained shear strength averaged over the contact area, $A_{p}$ or $A_{s}$.

The reference undrained shear strength adopted in Eq 28 is the idealized profile shown in Fig. $9(\mathbf{a})$, which is enhanced using a power law strain rate function (Biscontin and Pestana 2001; 
Peuchen and Mayne 2007; Randolph et al. 2007; O’Loughlin et al. 2013b) expressed as:

$$
R_{f}=\left(\frac{\dot{\gamma}}{\dot{\gamma}_{\text {ref }}}\right)^{\beta} \approx\left(n \frac{v / d}{(v / d)_{\text {ref }}}\right)^{\beta}
$$

where:

$\beta=$ the strain rate parameter,

$v / d=$ an approximation of the operational shear strain rate, and

the subscript "ref" = the reference shear strain rate associated with the measurement of the undrained shear strength.

The factor $n$ in Eq 29 accounts for the greater rate effects reported for shaft resistance compared to tip resistance (Dayal et al. 1975; Chow et al. 2014; Steiner et al. 2014) and is taken as $n=1$ for tip resistance (Zhu and Randolph 2011) and as a function of $\beta$ (adapted from Eq $8 \mathrm{~b}$ in Einav and Randolph 2006) for estimating rate effects in shaft resistance according to:

$$
n=2\left(\frac{n_{l}}{\beta}+n_{l}-2\right)
$$

where:

$n_{l}=1$ for axial loading.

The predictions on Fig. 17 were obtained using bearing capacity factors of $N=7.5$ for the leading and trailing edges of the flukes (analogous to a deeply embedded strip footing) and $N=12$ for the follower tip, but not for the padeye as the hole formed by the passage of the anchor was assumed to remain open. This is appropriate since ROV video capture of the drop sites (see Fig. 13) showed an open crater and the dimensionless strength ratio at the trailing end of the embedded DEPLA follower, $s_{u} / \gamma^{\prime} d=6.9$ (where $d$ is the diameter of the DEPLA sleeve and $\gamma^{\prime}$ is the effective unit weight of the soil), which is sufficient to maintain an open cavity above the follower (Morton et al. 2014; O'Beirne et al. 2015). Values for the drag coefficient, $C_{d}$, were determined from the free fall in the water phase of the tests, which gave an average $C_{d}=0.7$ (Blake and O'Loughlin 2015). The strain rate parameter was taken as $\beta=0.08$, which is typical of that measured in variable rate penetrometer testing (Low et al. 2008; Lehane et al. 2009) and approximates to an $18 \%$ change in strength per log cycle change in strain rate, typical of that measured in laboratory testing (e.g., Vaid and Campenella 1977; Graham et al. 1983; Lefebvre and LeBoeuf 1987). The interface friction ratio, $\alpha$, was varied to obtain the best match between the measured and predicted velocity profiles. The comparison between these on Fig. 17 indicates that the inclusion of a fluid-mechanics drag-resistance term is appropriate for projectiles penetrating soft clay at high velocities. There is excellent agreement between the measured and predicted velocity profiles using $\alpha=0.27$, which is within the range deduced from the cyclic piezoball remolding tests $(0.19$ to 0.33$)$. In contrast, the best agreement that could be obtained without the inclusion of drag resistance required $\alpha=0.38$, which is inconsistent with results from the cyclic piezoball remolding tests and gave a much poorer match.

\section{Conclusions}

This paper describes a fully self-contained low-cost MEMS-based IMU consisting of a tri-axis accelerometer and a three-component gyroscope, and considered sample data captured by the IMU during field tests on dynamically installed projectiles. Such data are important for understanding the soil-structure interactions that occur at the elevated shear strain rates associated with dynamic penetration events. To the authors' knowledge, these data are the first reported use of a 6DoF IMU for a geotechnical application.

A comprehensive framework for interpreting the IMU measurements so that they are coincident with a fixed inertial frame of reference was described and implemented to establish projectile rotations, accelerations, and velocities during free fall in water and embedment in soil. It is often the final embedment depth of a dynamically embedded projectile that is of interest. The paper showed that for projectiles that tilt during free fall, embedments calculated from the body frame acceleration measurements, rather than from accelerations transformed to an inertial frame of reference, led to derived embedment depths that were in error by up to $27 \%$. In contrast, embedment depths derived from IMU data interpreted from within an inertial frame of reference were shown to be in excellent agreement with independent direct measurements.

The merit of collecting motion data during dynamic penetration events was demonstrated by using the IMU data to validate an embedment prediction model based on strain rate enhanced shear resistance and fluid mechanics drag resistance for dynamically installed anchors. In this demonstration the inclusion of drag resistance during embedment in soil was shown to be appropriate, as the measured and predicted velocity profiles were in excellent agreement. In contrast, when drag resistance was omitted an interface friction ratio inconsistent with the measured soil sensitivity was required to match the final embedment depth, and as a consequence the overall agreement between the measured and predicted profiles was much poorer.

In conclusion, the use of a reliable IMU with an appropriate interpretation framework is required to successfully apply these projectile-based geotechnical devices.

\section{ACKNOWLEDGMENTS}

This work forms part of the activities of the Centre for Offshore Foundation Systems (COFS), currently supported as a node of the Australian Research Council Centre of Excellence for Geotechnical Science and Engineering and as a Centre of Excellence by the Lloyd's Register Foundation. The Lloyd's Register 
Foundation invests in science, engineering, and technology for public benefit, worldwide. The writers also acknowledge the support of Enterprise Ireland that funded the experimental work through their Commercialisation Fund Technology Development Programme.

\section{References}

Allmond, J. D., Hakhamaneshi, M., Wilson, D. W., and Kutter, B. L., 2014, "Advances in Measuring Rotation With MEMS Accelerometers," Proceedings of the Eighth International Conference on Physical Modelling in Geotechnics, Vol. 1, Perth, Australia, Jan 14-17, 2014, pp. 353-359.

Bennett, V., Abdoun, T., Shantz, T., Jang, D., and Thevanayagam, S., 2009, "Design and Characterization of a Compact Array of MEMS Accelerometers for Geotechnical Instrumentation," Smart Struct. Syst., Vol. 5, No. 6, pp. 663-679.

Biscontin, G. and Pestana, J. M., 2001, "Influence of Peripheral Velocity on Vane Shear Strength of an Artificial Clay," Geotech. Test. J., Vol. 24, No. 4, pp. 423-429.

Blake, A. P. and O'Loughlin, C. D., 2015, "Installation of Dynamically Embedded Plate Anchors as Assessed Through Field Tests," Can. Geotech. J., Vol. 52, No. 9, pp. 1270-1282.

Boukpeti, N., White, D. J., and Randolph, M. F., 2012, "Analytical Modelling of the Steady Flow of a Submarine Slide and Consequent Loading on a Pipeline," Géotechnique, Vol. 62, No. 2, pp. 137-146.

Casagrande, A. and Wilson, S. D., 1951, "Effect of Rate of Loading on the Strength of Clays and Shales at Constant Water Content," Géotechnique, Vol. 2, No. 3, pp. 251-263.

Chow, S. H. and Airey, D. H., 2010, "Laboratory Free Falling Penetrometer Test into Clay," Proceedings of the 2nd International Symposium on Frontiers in Offshore Geotechnics, Perth, Australia, Nov 8-10, 2010, pp. 265-270.

Chow, S. H., O’Loughlin, C. D., and Randolph, M. F., 2014, "Soil Strength Estimation and Pore Pressure Dissipation for Free-Fall Piezocones in Soft Clay," Géotechnique, Vol. 64, No. 10, pp. 817-827.

Cilingir, U. and Madabhushi, S. P. G., 2011, "A Model Study on the Effects of Input Motion on the Seismic Behaviour of Tunnels," Soil Mech. Earthq. Eng., Vol. 31, No. 3, pp. 452-462.

Colreavy, C., O'Loughlin, C. D., and Ward, D., 2012, "Piezoball Tests in a Soft Lake Sediments," Proceedings of the 4th International Conference on Geotechnical and Geophysical Site Characterisation, Porto de Galinhas, Brazil, Sept 18-21, 2012, pp. 597-602.

Dayal, U. and Allen, J. H., 1973, "Instrumented Impact Cone Penetrometer," Can. Geotech. J., Vol. 10, No. 3, pp. 397-409.

Dayal, U., Allen, J. H., and Jones, J., 1975, "Use of an Impact Penetrometer for the Evaluation of the In-Situ Strength of Marine Sediments," Marine Geores. Geotechnol., Vol. 1, No. 2, pp. 73-89.

Einav, I. and Randolph, M. F., 2006, "Effect of Strain Rate on Mobilised Strength and Thickness of Curved Shear Bands," Géotechnique, Vol. 56, No. 7, pp. 501-504.

Fossen, T. I., 2011, "Handbook of Marine Craft Hydrodynamics and Motion Control," Wiley, Chichester, UK.
Graham, J., Crooks, J. H. A., and Bell, A. L., 1983, “Time Effects on the Stress-Strain Behaviour of Natural Soft Clays," Géotechnique, Vol. 33, No. 3, pp. 327-340.

Jonkman, J. M., 2007, "Dynamics Modelling and Loads Analysis of an Offshore Floating Wind Turbine," Technical Report NREL/TP-500-41958, National Renewable Energy Laboratory, Golden, CO.

King, K., Yoon, S. W., Perkins, N. C., and Najafi, K., 2008, "Wireless MEMS Inertial Sensor System for Golf Swing Dynamics," Sensors Actuators, Vol. 141, No. 2, pp. 619-630.

Lefebvre, G. and LeBoeuf, D., 1987, "Rate Effects and Cyclic Loading of Sensitive Clays," J. Geotech. Eng., Vol. 113, No. 5, pp. 476-489.

Lehane, B. M., O'Loughlin, C. D., Gaudin, C., and Randolph, M. F., 2009, "Rate Effects on Penetrometer Resistance in Kaolin," Géotechnique, Vol. 59, No. 1, pp. 41-52.

Levy, F. M. and Richards, D. J., 2012, "Rapid Soil Displacements from MEMS Accelerometers," Proceedings of the 30th IMAC Conference on Structural Dynamics, Jacksonville, FL, Jan 30-Feb 2, 2012, Vol. 1, pp. 197-208.

Lieng, J. T., Hove, F., and Tjelta, T. I., 1999, “Deep Penetrating Anchor: Subseabed Deepwater Anchor Concept for Floaters and Other Installations," Proceedings of the 9th International Offshore and Polar Engineering Conference, Brest, France, May 30-June 4, 1999, pp. 613-619.

Low, H. E., Randolph, M. F., De Jong, J. T., and Yafrate, N. J., 2008, "Variable Rate Full Flow Penetration Tests in Intact and Remoulded Soil," Proceedings of the 3rd International Conference on Geotechnical and Geophysical Site Characterization, Taipei, Taiwan, April 1-4, 2008, pp. 1087-1092.

Morton, J. P. and O'Loughlin, C. D., 2012, "Dynamic Penetration of a Sphere in Clay," Proceedings of the 7th International Conference in Offshore Site Investigation and Geotechnics, London, UK, Sept 12-14, 2012, pp. 223-230.

Morton, J. P., O'Loughlin, C. D., and White, D. J., 2014, "Strength Assessment During Shallow Penetration of a Sphere in Clay," Géotechnique Lett., Vol. 4, No. 4, pp. 262-266.

Morton, J. P., O'Loughlin, C. D., and White, D. J., 2015, "Estimation of Soil Strength by Instrumented Free-Fall Sphere Tests," Géotechnique (to be published).

Nebot, E. and Durrant-Whyte, H., 1999, "Initial Calibration and Alignment of Low Cost Inertial Navigation Units for Land Vehicle Applications," J. Robot. Syst., Vol. 16, No. 2, pp. 81-92.

Noureldin, A., Karamat, T. B., and Georgy, J., 2012, Fundamentals of Inertial Navigation, Satellite-Based Positioning and Their Integration, Springer, Berlin.

O’Beirne, C., O'Loughlin, C. D., and Gaudin, C., 2015, "Soil Response in the Wake of Dynamically Installed Projectiles," Géotechnique Lett., Vol. 5, No. 3, 153-160.

O’Loughlin, C. D., Blake, A. P., Wang, D., Gaudin, C., and Randolph, M. F., 2013a, “The Dynamically Embedded Plate Anchor: Results from an Experimental and Numerical Study," Proceedings of the 32nd International Conference on Ocean, Offshore and Artic Engineering, Paper No. OMAE2013-11571, Nantes, France, June 9-14, 2013.

O’Loughlin, C. D., Richardson, M. D., Randolph, M. F., and Gaudin, C., 2013b, "Penetration of Dynamically Installed Anchors in Clay," Géotechnique, Vol. 63, No. 11, pp. 909-919. 
O’Loughlin, C. D., Gaudin, C., Morton, J. P., and White, D. J., 2014, "MEMS Accelerometer for Measuring Dynamic Penetration Events in Geotechnical Centrifuge Tests," Phys. Modell. Geotech., Vol. 50, No. 5, pp. 31-39.

Peuchen, J. and Mayne, P., 2007, "Rate Effects in Vane Shear Testing," Proceedings of the 6th International Conference on Offshore Site Investigation and Geotechnics, London, Sept 11-13, 2007, Society for Underwater Technology, London, pp. 187-194.

Randolph, M. F. and White, D. J., 2012, "Interaction Forces Between Pipelines and Submarine Slides-A Geotechnical Viewpoint," Ocean Eng., Vol. 48, No. 1, pp. 32-37.

Randolph, M. F., Low, H. E., and Zhou, H., 2007, "Keynote Lecture: In Situ Testing for Design of Pipeline and Anchoring Systems," Proceedings of the 6th International Conference on Offshore Site Investigation and Geotechnics, London, Sept 11-13, 2007, pp. 251-262.

Sahdi, F., Gaudin, C., White, D. J., Boylan, N., and Randolph, M. F., 2014, "Centrifuge Modelling of Active Slide-Pipeline Loading in Soft Clay," Géotechnique, Vol. 64, No. 1, pp. 16-27.

Sharma, A., 2007, "CMOS Systems and Circuits for Sub-Degree per Hour MEMS Gyroscopes," PhD thesis, Georgia Institute of Technology, Atlanta, GA.

Sheahan, T. C., Ladd, C. C., and Germaine, J. T., 1996, "RateDependent Undrained Shear Behaviour of Saturated Clay," J. Geotech. Eng., Vol. 122, No. 2, pp. 99-108.

Stegmann, S., Morz, T., and Kopf, A., 2006, "Initial Results of a New Free Fall-Cone Penetrometer (FF-CPT) for Geotechnical In Situ Characterisation of Soft Marine Sediments," Norwegian J. Geol., Vol. 86, No. 3, pp. 199-208.

Steiner, A., Kopf, A. J., L'Heureux, J. S., Kreieter, S., Stegmann, S., Haflidason, H., and Moerz, T., 2014, "In Situ Dynamic Piezocone Penetrometer Tests in Natural Clayey Soils-A
Reappraisal of Strain-Rate Corrections," Can. Geotech. J., Vol. 51, No. 3, pp. 272-288.

Stephan, S., Kaul, N., and Villinger, H., 2012, "The Lance Insertion Retardation (LIRmeter): An Instrument for In-Situ Determination of Sea Floor Properties-Technical Description and Performance Evaluation," Marine Geophys. Res., Vol. 33, No. 3, pp. 209-221.

Stovall, S. H., 1997, "Basic Inertial Navigation," Report NAWCWPNS TM 8128, Navigation and Data Link Section Systems Integration Branch, Naval Air Warfare Center Weapons Division, China Lake, CA.

Stringer, M. E., Heron, C. M., and Madabhushi, S. P. G., 2010, "Experience Using MEMS-Based Accelerometers in Dynamic Testing," Proceedings of the 7th International Conference on Physical Modelling in Geotechnics, Vol. 1, Zurich, Switzerland, June 28-July 1, 2010, pp. 389-394.

Tanaka, H. and Locat, J., 1999, “A Microstructural Investigation of Osaka Bay Clay: The Impact of Microfossils on Its Mechanical Behaviour," Can. Geotech. J., Vol. 36, No. 3, pp. 493-508.

Vaid, Y. P. and Campanella, R. G., 1977, "Time-Dependent Behaviour of Undisturbed Clay," J. Geotech. Eng, Vol. 103, No. 7, pp. 693-709.

Yafrate, N., DeJong, J., DeGroot, D., and Randolph, M. F., 2009, "Evaluation of Remoulded Shear Strength and Sensitivity of Soft Clay Using Full Flow Pentrometers," J. Geotech. Geoenviron. Eng., Vol. 122, No. 2, pp. 99-108.

Zhou, H. and Randolph, M. F., 2009, "Numerical Investigations into Cycling of Full-Flow Penetrometers in Soft Clay," Géotechnique, Vol. 59, No. 10, pp. 801-812.

Zhu, H. and Randolph, M. F., 2011, "Numerical Analysis of a Cylinder Moving Through Rate-Dependent Undrained Soil," Ocean Eng., Vol. 38, No. 7, pp. 943-953. 